\title{
Concurrent TMS-fMRI to determine adaptive brain changes to virtual lesions interfering with visual processing
}

\author{
Estelle RAFFIN ${ }^{1,2}$, Roberto F. SALAMANCA-GIRON ${ }^{1,2}$, Krystel R. HUXLIN ${ }^{3}$, Olivier \\ REYNAUD ${ }^{4}$, Loan MATTERA ${ }^{4}$, Roberto MARTUZZI ${ }^{4}$, Friedhelm C. HUMMEL ${ }^{1,2,5}$
}

${ }^{1}$ Defitech Chair in Clinical Neuroengineering, Center for Neuroprosthetics and Brain Mind Institute, EPFL, Geneva, Switzerland.

2 Defitech Chair in Clinical Neuroengineering, Center for Neuroprosthetics and Brain Mind Institute, Clinique Romande de Readaptation (CRR), EPFL Valais, Sion, Switzerland.

${ }^{3}$ The Flaum Eye Institute and Center for Visual Science, University of Rochester, Rochester, NY, USA.

${ }^{4}$ Human Neuroscience Platform, Fondation Campus Biotech Genève (FCBG), Campus Biotech, Geneva, Switzerland.

${ }^{5}$ Clinical Neuroscience, University of Geneva Medical School, Geneva, Switzerland.

Corresponding Author: Estelle Raffin, Defitech Chair of Clinical Neuroengineering, Center for Neuroprosthetics (CNP), Swiss Federal Institute of Technology (EPFL), Campus Biotech, Room H4.3.132.084, Chemin des Mines 9, 1202 Geneva, Switzerland., Email: estelle.raffin@epfl.ch

Keywords:

- Visual processing 
- TMS-fMRI

- Motion discrimination

- Regional and network activity

- State-dependency

\section{Abbreviations:}

BOLD, Blood oxygenation level dependent;

FEF, Frontal eye fields;

fMRI, Functional magnetic resonance imaging;

GLM, General linear model

ICA, Independent component analysis;

LGN, Lateral geniculate nucleus

mPFC, Medial prefrontal cortex;

ROI, Region of interest;

TMS, Transcranial magnetic stimulation

EVA, Primary visual cortex;

$\mathrm{hMT+/HMT+/V5,} \mathrm{Medio-temporal} \mathrm{cortex;}$

VOI, Volume of Interest 
bioRxiv preprint doi: https://doi.org/10.1101/2022.03.03.482512; this version posted March 4, 2022. The copyright holder for this preprint (which was not certified by peer review) is the author/funder. All rights reserved. No reuse allowed without permission.

\section{Acknowledgement}

We thank Holly Bridge for her insightful comments on the manuscript. We would like to thank the MRI and neuromodulation facilities of the Human Neuroscience Platform of the Fondation Campus Biotech Geneva, for technical advice. This study was supported by the Bertarelli Foundation (Catalyst BC77O7 to FCH \& ER), by the Swiss National Science Foundation (PRIMA PR00P3_179867 to ER), and by the Defitech Foundation (to FCH). 
Abstract:

Introduction: Understanding the causal relationship between a focal lesion and brain network (re)organization is a crucial step in order to accurately predict the resulting symptoms of the lesion and implement personalized rehabilitation strategies. Transcranial magnetic stimulation (TMS) can be used to create local and transient neural perturbations, the so-called "virtual lesion" approach. In this study, we tested how a virtual lesion applied to the Early Visual Areas (EVA) or the extrastriate, motion-sensitive, medio-temporal area (hMT+/V5) in different contexts affects behavior and changes neuronal network activity and organisation, assessed with functional magnetic resonance imaging (fMRI).

Methods: We applied short trains of $10 \mathrm{~Hz}$ TMS to healthy participants over the EVA or $\mathrm{hMT}+/ \mathrm{MT}$. This was done both at rest and at relevant times during a motion discrimination task, while concurrent fMRI was performed. Regional BOLD activity was analysed using a general linear model (GLM) and functional brain networks were assessed using independent component analysis (ICA). Motion direction discrimination and motion awareness were related to the imaging data.

Results: TMS applied over the EVA and hMT+/V5 induced transient modulation of motion perception and discrimination. Comparing resting versus active states, both TMS sites showed a common suppression of local and remote brain activity at rest while an over-activation of the stimulated areas and related networks were found during the task. More subtly, distinct dynamic and topological TMS-induced networks properties could be revealed depending on the exact visual processing stages TMS was applied at. In particular, brain networks associated with EVA stimulation showed a clear context-dependency and were spatially more restricted than for $\mathrm{hMT+/V5}$ stimulation.

Discussion: The present findings highlight the possibility of interfering with distinct visual processing stages and the possibility of imaging the local and remote neural correlates of the 
behavioral impact. They also confirm the complexity of TMS effects on BOLD activity, switching from signal suppression at rest to irrelevant neural noise addition during active visual processing, even differing throughout the time course of information processing. Moreover, the networks analyses suggest that the EVA might be more resilient to focal perturbations by means of a "virtual lesion" than hMT+/V5. As a critical processing center, the EVA may be important for maintaining stability in the visual network, whereas the perturbation of a more specialized region such as $\mathrm{hMT}+\mathrm{V} 5$ has greater impact on local and network activity, as well as on behavior. These findings add to the understanding of visual motion processing and especially to the impact and potential mechanism of focal lesions in this system. 


\section{Introduction:}

Brain activity is characterized by networks of coordinated brain areas that have a relatively stable spatiotemporal organization. Yet, they dynamically adjust to changing contexts and ongoing demands (Telesford et al., 2011) (Papo et al., 2014). Such adaptive networks can be characterized by their topological transformation, their state-dependency and/or their state transition. The adaptive nature of brain networks is likely important for maintaining an optimal balance of information segregation and integration, allowing functional stability, distal communication via long-range connections, all while maximizing the efficiency of local processing. This process might support functional networks resilience in case of progressive neurodegeneration or focal lesions (Bullmore and Sporns, 2012) (Bassett and Bullmore, 2009) (Fornito et al., 2015). For instance, focal or incomplete brain lesions can sometimes fail to produce any behavioural effect (Sperber, 2020). In contrast, small lesions located in highly interconnected hubs can have devastating effects (Egger et al., 2021). Today, a comprehensive understanding of the causal relationship between a focal lesion and brain network organization is still missing, leading to the inability to accurately predict resulting symptoms and recovery processes.

Directly testing this relationship in humans is challenging because of the difficulties inherent in selectively altering activity in vivo to dissect causal impact on brain networks. An emerging approach developed to counteract this challenge is to combine non-invasive brain stimulation (e.g., transcranial magnetic stimulation, TMS or transcranial electric stimulation, tES) with neuroimaging techniques (in particular functional magnetic resonance imaging (fMRI) and electroencephalography (EEG)) (e.g., Peña-Gómez et al., 2012) (Ozdemir et al., 2020) (Peters et al., 2020). The combination of TMS with fMRI provides an unique opportunity to temporarily "knock out" a brain region and assess the changes in local excitability or inter-areal functional connectivity, which may underlie changes in task performance (Ruff et al., 2006a) (Bestmann S., 


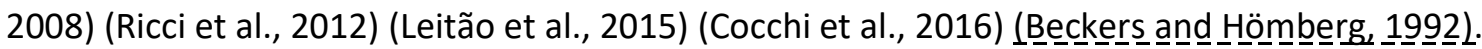
When applied as time-locked single pulses or trains of pulses, TMS can be used to transiently disrupt the function of a target cortical area and modify behavior - in essence creating a temporary, "virtual lesion" in a healthy brain (Pascual-Leone et al., 1999). The first use of the TMS-induced virtual lesion concept was in early visual cortex, where stimulation prevented the detection of visual targets (Amassian et al., 1989). Then, several combined TMS-induced virtual lesion studies with $\mathrm{fMRI}$ assessed the impact that focal virtual lesions can have on patterns of functional connectivity in specialized, large-scale, brain systems (Ruff et al., 2006b) (Grefkes et al., 2010) (Eldaief et al., 2011) (Fox et al., 2012) (Watanabe et al., 2013) (Petitet et al., 2015) (Jung et al., 2020a). Cocchi and colleagues provided an elegant illustration of subsequent homeostatic reconfigurations of intrinsic interactions within the visual system (Cocchi et al., 2016). They found that inhibitory theta burst stimulation of the early visual cortex selectively increased feedforward interactions, especially with FEF and extrastriate visual areas. In turn, stimulation of the FEF decreased feedback interactions with low-level visual areas.

In this study, we compared the behavioural consequences, as well as the local and network activation, associated with TMS-induced virtual lesions (Alexander et al., 2018) (Rademaker et al., 2017) (van de Ven and Sack, 2013) applied to the Early Visual Areas (EVA) or to the extrastriate, motion-sensitive visual area MT (hMT+/V5). More precisely, we investigated whether there would be any difference on how the brain reacts to these focal lesions affecting a primary integrative/multimodal brain region like the EVA acting as a gateway to other, 'higher' visual areas of the brain, compared to a more functionally specialized brain region, such as hMT+/V5 (Rubinov and Sporns, 2010) (van den Heuvel and Sporns, 2013) (Tu et al., 2021). Any difference in robustness to EVA lesion or to $\mathrm{hMT}+\mathrm{V} 5$ lesion might be explained by the degree of distributed networks underlying the TMS effects. 
Because TMS modulation of visual network dynamics is certainly influenced by ongoing task demands, we compared the changes in regional BOLD activity and in functional connectivity at rest and during a motion discrimination task. Moreover, the precisely timed application of TMS bursts allowed the focal and dynamic perturbation of a targeted neural process (e.g., Kammer et al., 2005b) (Cowey et al., 2006) (Laycock et al., 2007a) (Grasso et al., 2018). Therefore, we used two different latencies for each stimulated area to perturb specific signaling routes within the visual hierarchy (Laycock et al., 2007a) (Gilaie-Dotan, 2016). Functional connectivity was measured using independent component analysis (ICA-) based network decomposition. This approach enabled us to capture network dynamics of the targeted networks in response to focal virtual lesions.

Given the existing literature on state-dependent TMS effects (Silvanto et al., 2007) (Blankenburg et al., 2010) (Leitão et al., 2015) (Jung et al., 2020b), we anticipated different BOLD activity changes in response to the TMS-induced virtual lesions when applied at rest or during the motion direction discrimination task. Moreover, based on earlier evidence in monkeys and rodents suggesting that state-dependency increases along the visual hierarchy (Haenny and Schiller, 1988) (Piasini et al., 2021), we expected that behavioral perturbation, TMS-induced activity and signal propagation would differ according to the target area and the visual state. We anticipated that TMS over hMT+/V5 would be more detrimental to the task considering the increasing evidence of differential impact of integrative hubs versus unimodal specialized nodes on network dynamics (Das et al., 2012) (Gollo et al., 2017) (Tu et al., 2021). 


\section{Materials and Methods}

\subsection{Participants}

Sixteen healthy subjects (nine males: mean age 26.5 years, range 19-32 years) were recruited for the two main experimental sessions. All participants provided informed written consent prior the experiment and none of them met the MRI or TMS exclusion criteria (Rossi et al., 2021). This study was approved by the local Swiss Ethics Committee (2017-01761) and performed in accordance with the Declaration of Helsinki.

\subsection{Experimental Design and Task Procedure}

All participants (besides one drop-out for the second session) performed two TMS-fMRI sessions. During the first session, TMS was applied to the right EVA (TMS(EVA): mean( \pm SD) MNI coordinate: $8(5) ;-76(4) ; 9(6))$; during the second session, TMS was applied to the functionally defined right hMT+/V5 (TMS $\left(\mathrm{hMT}_{+} / \mathrm{N5}\right)$ : mean MNI coordinates (SD): 46(4); -83(6); 11(5)) (Figure 1A). Both sessions had the same content except the anatomical T1-MPRAGE sequence and the hMT+/V5 functional localizer sequence, which were only performed during the first session. A short offline session prior the hMT+/V5 session was needed to locate the individual HMT+/V5 cluster using a neuro-navigation system (Localite $\mathrm{GmbH}$, Bonn, Germany). The measurements comprised:

- A Rest TMS sequence, during which an event-related design was used to map the effect of TMS bursts composed of three pulses at alpha $(10 \mathrm{~Hz})$ frequency. Three conditions were pseudorandomized and counterbalanced across the run: high-intensity TMS (HighTMS), lowintensity TMS (LowTMS) and no TMS (noTMS), with 25 repetitions of each condition with an inter-trial interval (ITI) of 6 seconds (covering 3 repetition times). The TMS intensity was set to 
$\approx 80 \%$ [range: 75 to $90 \%$ ] maximal stimulator output (MSO) for the HighTMS condition, and $\approx 38$ \% [35 to 43\%] MSO for the LowTMS condition. Intensity was individually adjusted prior the measurement to ensure phosphene sub-threshold stimulation and to avoid pain or discomfort. Participants were asked to look at a fixation cross throughout the acquisition, displayed in the middle of a $44 \mathrm{~cm} \times 27 \mathrm{~cm} \mathrm{LCD} \mathrm{monitor} \mathrm{at} \mathrm{a} 2.5 \mathrm{~m}$ distance via a mirror mounted on the head coil or on a frame on top of the TMS-fMRI setup.

- A Task TMS sequence during which participants had to rate their subjective perceptual experience of visually presented motion stimuli and to perform a forced-choice direction discrimination task on the same moving stimuli (Koivisto et al., 2021). The visual stimuli involved a group of white dots in a $5^{\circ}$ diameter circular aperture centered in the middle of the screen. The dots were either static or moving coherently to the right or to the left at a density of 2.6 dots per degree. Dots were displayed for 50, 67 or $84 \mathrm{~ms}$ (corresponding to 3, 4 or 5 frames). This duration was individually adjusted prior the fMRI measurement to ensure approximatively 70\% accuracy in the noTMS trials. TMS bursts were applied using the same, individually-defined parameters of the HighTMS condition described above. In the main experimental conditions, TMS bursts were given when visual signals first reach EVA or hMT+/V5, respectively $60 \mathrm{~ms}$ and $30 \mathrm{~ms}$ after stimulus onset $\left(\mathrm{TMS}_{(\mathrm{EVA})}\right.$ and $\left.\mathrm{TMS}_{(\mathrm{hMT}+\mathrm{NS})}\right)$. Regarding EVA, this timing is likely to reflect the role of EVA in feeding information forward to the extrastriate areas (Lamme, 2001). Over $\mathrm{hMT}+\mathrm{V} 5$, the $30 \mathrm{~ms}$ latency is thought to account for the direct thalamic-extrastriate pathway (Lamme and Roelfsema, 2000) (Beckers and Homberg, 1992) (Allen et al., 2014) (A. A. L. d'Alfonso et al., 2002) (A. A. d'Alfonso et al., 2002) (Koivisto et al., 2010) (Ruzzoli et al., 2011). These TMS onsets were tested offline in an independent subset of nine participants (data not presented here) prior the experiment to ensure a relatively consistent behavioral effect. This was done to determine critical timings of activation of EVA and hMT+/V5, throughout the first 150 ms after visual target onset in the motion discrimination task. It ensured that TMS at these precise timings induced a reliable behavioural disturbance. 
Two TMS onsets for each stimulation site were tested to compare the behavioral and neural consequences of interfering with other visual processing loops. On separate trials, TMS bursts were applied $150 \mathrm{~ms}$ after stimulus onset for EVA (TMS (EVAlate) and $130 \mathrm{~ms}$ for hMT+/V5

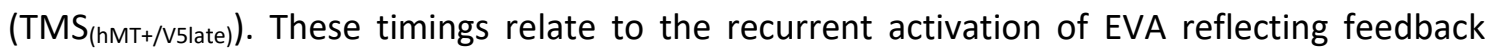
processing from high visual areas (Lamme et al., 1998) (Lamme and Roelfsema, 2000) (Laycock et al., 2007a). Concerning hMT+/V5, this timing represents the latency of the feedforward sweep reaching but could also be explained by feedback signals from frontal regions (Lamme and Roelfsema, 2000) (Hochstein and Ahissar, 2002) (Lamme, 2001).

For both EVA and hMT+/V5 sessions, all the conditions were repeated 25 times and randomized throughout the task: $\left[\mathrm{TMS}_{(\mathrm{EVA} / \mathrm{hMT}+/ \mathrm{VS})}+\right.$ moving dots], $\left[\mathrm{TMS}_{(\mathrm{EVA} / \mathrm{hMT}+\mathrm{N} 5)}+\right.$ static dots], [noTMS + moving dots], [noTMS + static dots], $\left[\mathrm{TMS}_{(\mathrm{EVAlate} / \mathrm{hMT}+/ \mathrm{NSlate)}}+\right.$ moving dots], $\left[\mathrm{TMS}_{(\mathrm{EVAlate} / \text { V5late) }}+\right.$ static dots] giving a total of 150 trials. Just after the stimulus presentation, participants were asked to subjectively rate their perception using a response box on their right hand with a 1 to 4 scale, 1 being "I clearly saw the motion" (Seeing), 2 being "I sensed the motion" (Sensing), 3 being "I saw something moving but I'm unable to judge the direction" (No Direction) and 4 being "I didn't see any motion" (No Motion) (Koivisto et al., 2010) (Grasso et al., 2018). These subjective ratings were used to compare conscious motion discrimination levels across conditions. When the participants pressed the three first options, they were then asked to judge whether the dots moved to the right or to the left with a response box on their left hand. If participants pressed 4, the task moved to the next trial. An inter-trial interval (ITI) of approximatively $1.5 \mathrm{sec}$ was used (see Figure 1B for an illustration of the task). To exclude bad performance due to TMS-induced blinking and to make sure that participants were constantly looking at the fixation point, gaze and pupils' movements were controlled in real time with an EyeLink 1000 Plus Eye Tracking System (SR Research Ltd., Canada) in the scanner, sampling at a frequency of $1000 \mathrm{~Hz}$. Trials were aborted and redone if deviation exceeded $1^{\circ}$ from the fixation point. 


\section{A. TMS targeting}

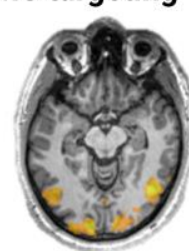

B. Task protocol

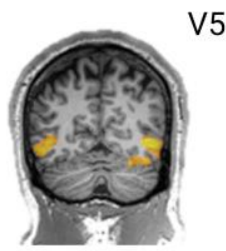

V5

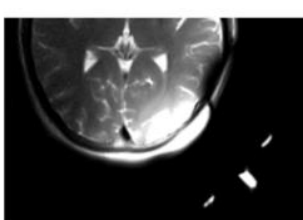

C. TMS-fMRI synchronization
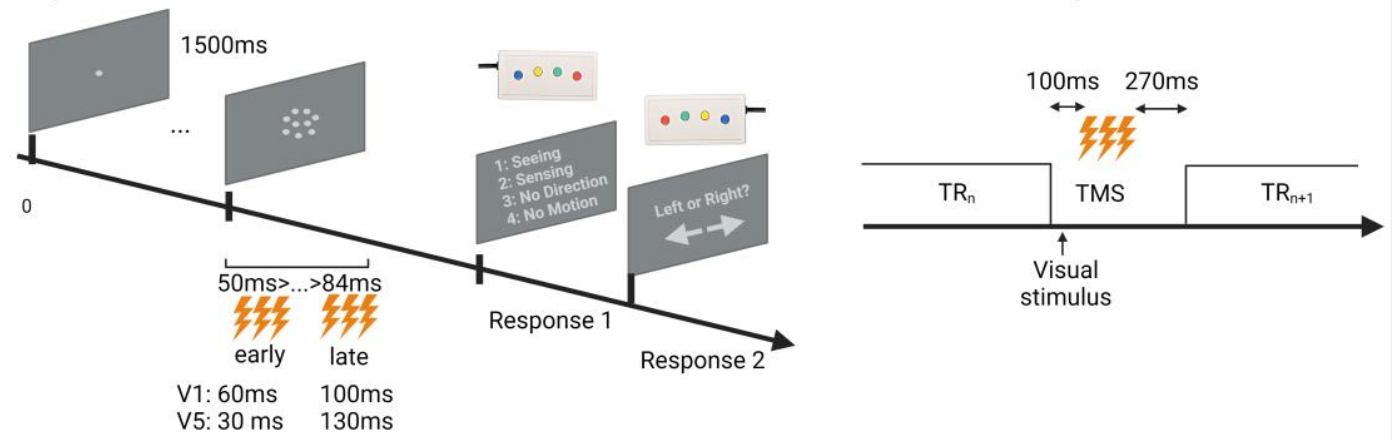

Figure 1.A: TMS targeting showing the functional localizer of EVA and hMT+/V5 for precise TMS positioning. The right images show a T2 image of a representative subject with the oil capsules placed on the TMS-MRI coil casing to monitor the coil position located on the TMS coil for V1 and V5. B: Timeline of a single trial of the motion discrimination task; D: Schematic of the BOLD sequence allowing artefact free combination of alpha TMS bursts.

- $h M T+/ V 5$ localizer: A standard hMT+/V5 localizer task was used to accurately and individually target the $\mathrm{hMT+} / \mathrm{V} 5$ area. The screen displayed radially moving dots alternating with stationary dots (see e.g., (Sack et al., 2007)). A block design alternated six $15 \mathrm{~s}$ blocks of radial motion with six blocks featuring stationary white dots in a circular region on a black background. This region subtended $25^{\circ}$ visual angle, with 0.5 dots per square degree. Each dot was $0.36^{\circ}$ diameter. In the motion condition the dots repeatedly moved radially inward for $2.5 \mathrm{~s}$ and outward for $2.5 \mathrm{~s}$, with $100 \%$ coherence, at $20^{\circ} / \mathrm{s}$ measured at $15^{\circ}$ from the center. Participants were passively looking at the screen and were asked to focus on a fixation point located in the middle of the screen. 
MRI images were acquired at the Magnetic Resonance Imaging facility of the Human Neuroscience Platform of the Fondation Campus Biotech Genève (FCBG, Biotech Campus, Geneva, Switzerland), using a Siemens Prisma 3 Tesla scanner (Siemens Healthineers, Germany).

\section{Standard MRI sequences acquisition}

Anatomical images were acquired with a 64-channel head and neck coil using a 3D MPRAGE sequence $\left(T R / T E=2300 / 2.96 \mathrm{~ms}\right.$, flip angle $9^{\circ}, 192$ sagittal slices, matrix $=256,1 \times 1 \times 1 \mathrm{~mm}^{3}$ resolution) covering the whole head. The hMT+/V5 localizer was acquired using a GE-EPI sequence with 56 axial slices, slice thickness $=2.2 \mathrm{~mm}$, in-plane resolution $=2.2 \mathrm{~mm}, \mathrm{TR}=2000$ $\mathrm{ms}, \mathrm{TE}=30 \mathrm{~ms}, \mathrm{FOV}=242 \mathrm{~mm}$, flip angle $=60^{\circ}, \mathrm{GRAPPA}=2$, Multiband Factor $(\mathrm{MB})=2$. For retrospective distortion correction, static field mapping was performed with a double-echo spoiled gradient echo sequence $(T R=652 \mathrm{~ms}$, $T E 1 / T E 2=4.92 / 7.38 \mathrm{~ms}$, resolution $2.2 \times 2.2 \times 2.2$ $\mathrm{mm}^{3}$, whole head coverage), generating two magnitude images and one image representing the phase difference between the two echoes.

\section{Combined TMS-fMRI sequences acquisition}

For combined TMS-fMRI images, two dedicated coil arrays were used (Navarro de Lara et al., 2017). This setup consisted of an ultra-slim 7-channel receive-only coil array, which was placed between the subject's head and the TMS coil (MRi-B91, MagVenture, Farum, Denmark) and connected to a MagPro XP stimulator (MagVenture, Farum, Denmark). A second, receive-only MR coil was positioned over $\mathrm{Cz}$ in the EEG 10-20 system to allow a full coverage of the participant's brain.

The Rest TMS and Task TMS sequences were acquired with a GE-EPI sequence using the same parameters: 40 axial slices, slice thickness $=2.2 \mathrm{~mm}$, in-plane resolution $=2.2 \mathrm{~mm}, \mathrm{TR}=2000$ $\mathrm{ms}, \mathrm{TE}=30 \mathrm{~ms}, \mathrm{FOV}=242 \mathrm{~mm}$, flip angle $=67^{\circ}, \mathrm{GRAPPA}=2$, Multiband Factor $(\mathrm{MB})=2$. A gap was introduced between consecutive EPI volumes in order to guaranty artefact free MR images after TMS stimulation (Navarro de Lara et al., 2015). For both rest and task TMS sequence, a 
single repetition time ( $T R=2000 \mathrm{~ms}$ ) was therefore composed of 40 slices acquired during 1430 ms followed by a gap of 570 ms before the next volume acquisition. During the Task TMS sequence, the visual stimulus appeared at the beginning of the gap, followed by the triplet of TMS at the onset defined earlier (see Figure 1C). The synchronization of TMS pulse was carried out with an in-house script using Matlab (R2019).

Static field mapping was also performed with the TMS-MRI coils using the same double-echo spoiled gradient echo sequence $(T R=652 \mathrm{~ms}, T E=4.92$ and $7.38 \mathrm{~ms}$, slice thickness: $2.2 \mathrm{~mm}$, inplane resolution $=2.2 \mathrm{~mm}$, flip angle $=60^{\circ}$ ) that generates two magnitude images and one image representing the phase difference between the two echoes.

To improve TMS targeting accuracy, several oil capsules were placed on the TMS-MRI coil casing to monitor the coil position prior to stimulation. These markers formed a "T-like shape" indicating the center of the coil as well as the coil orientation as seen on a T2 HASTE image acquired with the two TMS-compatible MRI coil arrays (56 axial slices, slice thickness $=0.8 \mathrm{~mm}$, $\mathrm{TR}=1500 \mathrm{~ms}, \mathrm{TE}=135 \mathrm{~ms}, \mathrm{FOV}=216 \mathrm{~mm}$, flip angle $=140^{\circ}$ ) (see Figure 1D for EVA on the left and $\mathrm{hMT}+/ \mathrm{V} 5$ on the right). Coil positions were readjusted if needed.

Functional and structural MR data, respectively acquired with the TMS-MRI coils and the 64channel head coil, were found extremely difficult to co-register due to different coil coverage, sensitivity and contrast. Therefore, two additional rapid high signal-to-noise, balanced, steadystate free precession (SSFP) sequences (Bieri and Scheffler, 2013) (96 axial slices, slice thickness $=2 \mathrm{~mm}$, (gap $0.4 \mathrm{~mm})$, in-plane resolution $=2 \mathrm{~mm}, \mathrm{TR}=5.24 \mathrm{~ms}, \mathrm{FOV}=256 \mathrm{~mm}$, flip angle $\left.=28^{\circ}\right)$ were acquired with both the TMS-MRI coils and the body coil integrated into the scanner bore in order to resolve based on the same SSFP contrast the coil coverage mismatch within the registration processing pipeline.

\subsection{Preprocessing of fMRI images}


Statistical Parametric Mapping software (SPM12, Wellcome Department of Imaging Neuroscience, UK) was used for data pre-processing and analysis of the four datasets (Rest TMS and Task TMS datasets, on both EVA and hMT+/V5). Spatial distortions due to field inhomogeneities were removed from all EPI images using the Fieldmap toolbox from SPM12 (Andersson et al., 2001). Subsequently, all time-series were motion-corrected to the first volume using 6 degrees of freedom ( 3 rotations, 3 translations) and drifts in signal time courses were corrected as well. To improve the normalization procedure, two intermediate steps were added. A first co-registration was performed between the mean realigned and slice timing corrected image and the SSFP sequence acquired with the same MR coil (and thus the same spatial coverage). The resulting, co-registered image was once more co-registered to the SSFP sequence acquired with the MR coil integrated into the scanner (i.e., the body coil, thus preserving the contrast). The latter could then be easily co-registered to the high resolution T1 image acquired with the 64-channel head coil that covered the whole brain, and later transformed into standard MNI space using a segmentation-based normalization approach (Ashburner and Friston, 2005). Finally, the normalized images were spatially smoothed using a Gaussian kernel $(4 \mathrm{~mm}$, Fullwidth half-maximal). The realignment parameters estimated during spatial pre-processing for the Rest TMS and Task TMS dataset were introduced in the design matrix as regressors of no interest in order to prevent confounding activations related to minor head movements during scanning. The experimental event-related designs were convolved with the canonical hemodynamic response function, and the resulting models described in the following section were estimated using a high-pass filter at $128 \mathrm{~s}$ to remove low-frequency artefacts.

\section{5 fMRI Univariate Analysis}

EVA and hMT+/V5 datasets were similarly analyzed using general linear models (GLM) to calculate individual contrasts. For the Task TMS sequence, a design matrix with TMS conditions 
(TMS, TMSlate, noTMS) and visual state (Moving, Static) was constructed. For the group analysis, paired-t-tests were conducted to assess the effect of TMS (TMS versus noTMS), the effect of TMS onset (TMS versus TMSlate) and the visual state (Moving versus Static). For the Rest TMS sequence, we defined a design matrix comprising three conditions (HighTMS, LowTMS and noTMS). T-contrasts for each TMS condition were established for all participants. For the purpose of this study, we only contrasted HighTMS versus noTMS using a paired-t-test at the group analysis. The statistical significance threshold was set to a height threshold of $p<0.001$ uncorrected, at the voxel level and to that of $p<0.05$ at the cluster level after false-discovery rate (FDR) correction. Group analyses were conducted using the GLMFlex Fast2 tookbox (https://habs.mgh.harvard.edu/researchers/data-tools/glm-flex-fast2/).

To explore the effect of TMS conditions within the visual network, mean beta values were extracted from regions of interest (ROIs) defined as a $8 \mathrm{~mm}$ radius sphere based on the results of the group-level analysis of the task the motion discrimination (Task fMRI) using the MarsBaR toolbox (Brett et al., 2002). These lateralized ROls included the right EVA $(6,-83,11)$, right hMT+/V5 $(58,-66,-3)$, right FEF $(38,-2,45)$, right IPS $(12,-82,36), \operatorname{SMAr}(6,5,54)$. For each site of stimulation (EVA and hMT+/V5) in the Task TMS condition, paired-t-tests were built (TMS versus noTMS and TMS versus TMSlate) as within subject factor. For the Rest TMS condition, a paired-t-test (TMS versus noTMS) was conducted for each ROI.

\section{6 fMRI Multivariate Analysis:}

Independent Component Analysis (ICA) was used to estimate independent spatiotemporal functional networks from the data. ICA uses fluctuations in BOLD signal to split it into maximally independent spatial maps or components, each explaining a unique part of variance from the 4D fMRI data. Then, all components have their specific time course related to a coherent neural signal potentially associated with intrinsic brain networks, artifacts, or both. The group ICA of 
fMRI Toolbox (GIFT version 3.0b; (Calhoun et al., 2001)) was used. First, it concatenates the individual data followed by the computation of subject-specific components and time course. Maximum Description Length (MDL) and Akaike's criteria were applied to estimate the number of ICs in our data. Using principal component analysis, individual data was reduced. Then, the informax algorithm (Bell and Sejnowski, 1995) was applied for the group ICA and estimated 16 components. In order to improve the IC's stability, the ICASSO was applied and run 20 times (Himberg et al., 2004). Of 16 components, three components for the hMT+/V5 Rest TMS and Task TMS, one for the EVA Rest TMS and two for the EVA Task TMS data were related to residual artifact and excluded for further analysis. The remaining components were defined as brain networks. We labelled the TMS specific networks defined by the overlap between the activated cluster and the coordinates of the stimulation target and other functional or domain-general networks (e.g., default mode network: DMN, visual network: VN or sensorimotor network: SMN). Based on these independent components, we applied several additional analyses:

a) we examined how each condition of the EVA/ hMT+/V5 Rest or Task experiment relates to the different networks using the temporal sorting in the GIFT toolbox. Temporal sorting consists in regressing the $\mathrm{fMRI}$ specific time course for each individual against the design matrix for the experimental conditions. The resulting betas weights represent the degree to which network was recruited by the conditions. For a network, positive and negative $b$ weights indicate the level of network recruitment in each experimental condition. Paired t-tests were used to identify networks that were significantly modulated by TMS at rest and during motion discrimination (qFDR-corrected $<0.05$ ) (Bonferroni corrected, $\mathrm{p}<0.05$ ). 


\section{Results}

\subsection{Univariate analysis}

\subsubsection{Inhibition of the stimulated regions at rest}

At rest, the fMRI contrast TMS versus noTMS revealed local suppressive effects for the stimulation over both EVA and hMT+/V5. For $\mathrm{TMS}_{(\mathrm{EVA})}$, decreased regional activity was found in the ipsilateral EVA, hMT+/V5 and IPS as confirmed by the ROI analysis (TMS (EVA) versus noTMS in EVA: $t_{(15)}=4.47, p=0.0004, h M T+/ V 5: t_{(15)}=2.8, p=0.01$, IPS: $\left(t_{(15)}=1.8, p=0.09\right)$ (Figure 4A and Supplementary Tables S1). TMS $(h M T+/ N 5)$ revealed negative clusters in the ipsilateral hMT+/V5, EVA, and also remotely in the FEF, as further confirmed by the ROI analysis (TMS $(h M T+/ N 5)$ versus noTMS in $h M T+/ V 5: \mathrm{t}_{(15)}=2.06, \mathrm{p}=0.059$, EVA $\left(\mathrm{t}_{(15)}=3.55, \mathrm{p}=0.003, \mathrm{FEF}:\left(\mathrm{t}_{(15)}=3.62, \mathrm{p}=0.003\right.\right.$, Figure $4 \mathrm{~B}$ and Supplementary Tables S2). Of interest, $T M S_{(E V A)}$ also increased activity in remote areas namely the SMA and the FEF (ROI analysis, SMA: $\mathrm{t}_{(15)}=2.52, \mathrm{p}=0.023$ and FEF: $\mathrm{t}_{(15)}=2.14$, $p=0.049)$.

\section{A. $\mathrm{TMS}_{(\mathrm{EVA})}>$ noTMS contrast}
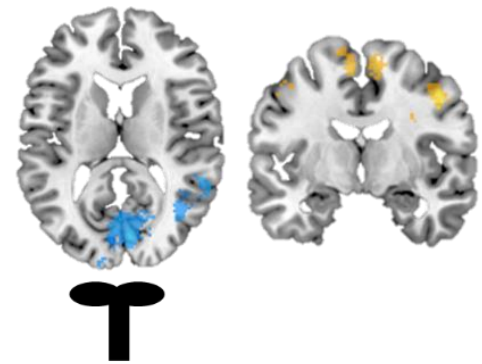

\section{B. TMS $_{(\mathrm{EVA})}$ ROI analysis}

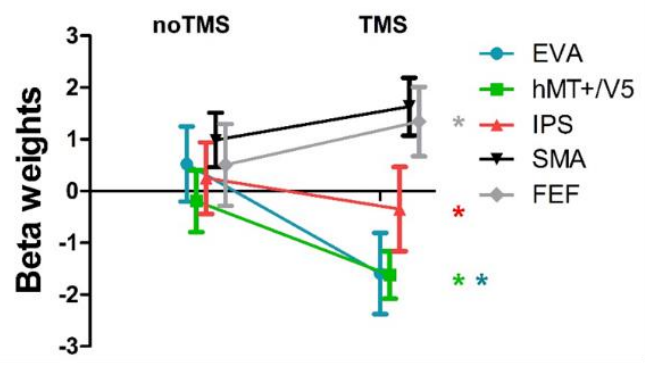

\section{C. $\mathrm{TMS}_{(\mathrm{hMT}+/ \mathrm{VS})}>$ noTMS contrast}

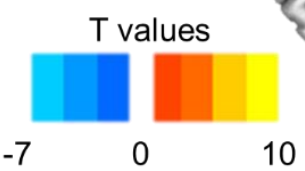

D. $\mathrm{TMS}_{(\mathrm{hMT}+/ \mathrm{V5})}$ ROI analysis

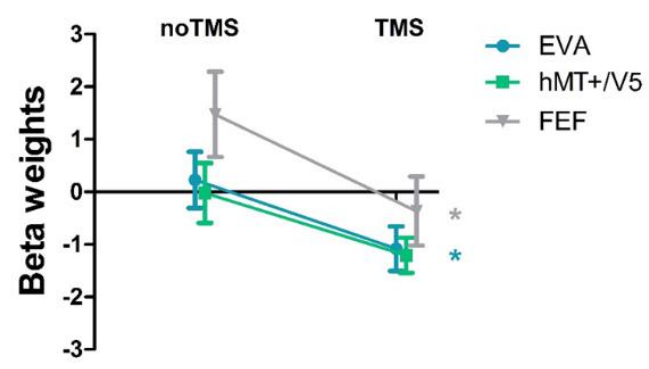


Figure 2A: $\mathrm{TMS}_{(\mathrm{EVA})}>$ noTMS contrast; B: TMS (EVA) $R O \mathrm{Tl}_{\text {analysis; }}$ C: $\mathrm{TMS}_{(\mathrm{hMT}+\mathrm{NS})}>$ noTMS contrast; $\mathbf{D}$ : TMS $\mathrm{TMT}_{(\mathrm{N}) \mathrm{S})} \mathrm{ROI}$ analysis; EVA: primary visual cortex; V5: Mediotemporal cortex; IPS: Inferior Parietal Sulcus; SMA: Supplementary Motor Area; FEF: Frontal Eye Field.

3.1.2 Behavioral effects of TMS (EVA) $_{\text {and } T M S_{(h M T+/ N 5)} \text { shows detriment in motion discrimination }}$ and awareness

Figure $3 \mathrm{~A}$ shows the mean accuracy (+/- SEM) obtained for the motion discrimination task without TMS and when a TMS burst was applied over EVA or hMT+/V5 (early onset: $\mathrm{t}=60 \mathrm{~ms}$ for $E V A, t=30 m s$ for $h M T+/ V 5)$. A repeated measure ANOVA revealed no global effect of Site $\left(F_{(1,15)}\right.$ $=0.85, p=0.37)$, but a main effect of TMS $\left(F_{(1,15)}=24.8, p<0.001\right)$ and no significant TMS by Site interaction $\left(F_{(1,15)}=1.62, p=0.22\right)$.

A. Global performances

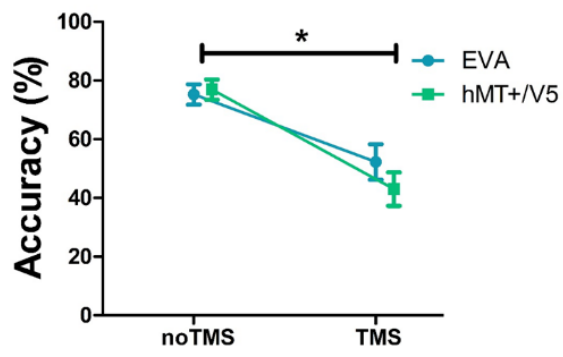

B. $\mathrm{TMS}_{(\mathrm{EVA})}$ and motion awareness

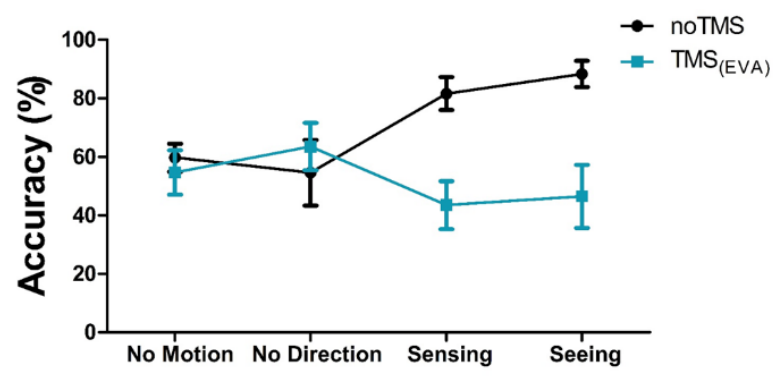

C. $\mathrm{TMS}_{(\mathrm{hMT}+/ \mathrm{VS})}$ and motion awareness

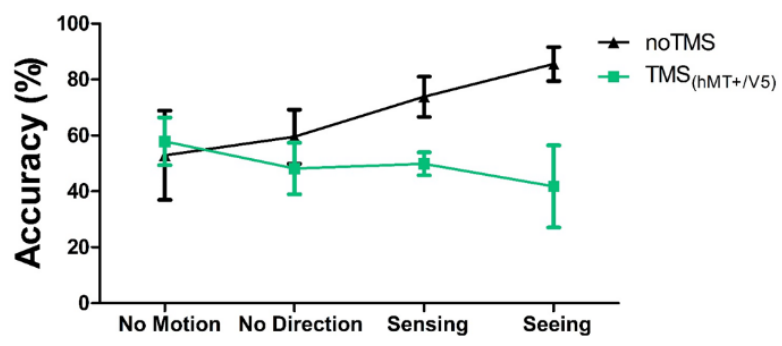

Figure 3: A: Mean (SEM) accuracy at the motion discrimination task with and without TMS and for both EVA and hMT+/V5 sessions; B: Relationship between behavioural accuracy and awareness of motion with $\mathrm{TMS}_{(\mathrm{EVA})}$ or without TMS; C: Relationship between behavioural accuracy and awareness of motion with $\mathrm{TMS}_{(\mathrm{hMT}+\mathrm{NS})}$ or without TMS. 
Additionally, we compared motion awareness across conditions to evaluate whether TMS over EVA and $\mathrm{hMT}+/ \mathrm{V} 5$ alters the conscious processing of motion direction. Table 2 reports the occurrence of each rating for the different conditions.

Table 2: Occurrence of trials in the four perceptual ratings with respect to the TMS conditions

\begin{tabular}{|l|l|l|l|l|}
\hline & \multicolumn{2}{c}{ EVA session } & hMT+/V5 session \\
\hline & noTMS & TMS & noTMS & TMS \\
\hline “No Motion" & $6 \%(3)$ & $22 \%(8)$ & $8 \%(12)$ & $17 \%(28)$ \\
\hline “No Direction" & $14 \%(7)$ & $23 \%(18)$ & $11 \%(6)$ & $16 \%(11)$ \\
\hline "Sensing" & $26 \%(13)$ & $37 \%(11)$ & $26.4 \%(11)$ & $33 \%(8)$ \\
\hline "Seeing" & $48 \%(28)$ & $20 \%(5)$ & $54 \%(21)$ & $44 \%(9)$ \\
\hline
\end{tabular}

More interestingly, we examined the relationship between awareness and accuracy (Figure 3B \& 3C). Without TMS, motion direction discrimination increased (moved away from chance level) as subjective awareness of motion increased. This indicates that without TMS, performances are tied to conscious motion awareness. Confirming the global decrease in performance, there was a significant TMS condition effect $\left(F_{(1,6)}=13.5, p=0.047\right)$. Importantly, we report a significant Rating by TMS condition interaction $\left(F_{(3,6)}=55.8, p<0.001\right)$, most likely explained by the impaired aware performance for both $\mathrm{TMS}_{(\mathrm{EVA})}$ and $\mathrm{TMS}_{(\mathrm{VS})}$ (i.e., rated as "Seeing" and "Sensing") compared to noTMS (for TMS $\mathrm{TEVA}_{\text {): }} \mathrm{t}_{(15)}=5.47, \mathrm{p}<0.001, \mathrm{TMS}_{(\mathrm{V})}$ : $\mathrm{t}_{(14)}=5.81, \mathrm{p}<0.001$ ). Unaware performances ("No Motion" and "No Direction") were unchanged for both conditions (all t-tests $>0.05)$. 
The fMRI contrast TMS (EVA) versus noTMS during both visual conditions (moving and static dots) revealed increased BOLD signal over the stimulated EVA area and over one higher level area (SMA). The same contrast for $T M S_{(h M T+N 5)}$ yielded an over-activation of the stimulated hMT+/V5 region and of the downstream EVA area (Figure 4A and 4C, Supplementary Tables S5 and S6). The ROI analysis confirmed the over-activation (for TMS $(\mathrm{EVA}), \mathrm{EVA}: \mathrm{t}_{(12)}=3, p=0.01, \mathrm{SMA}_{\mathrm{A}} \mathrm{t}_{(14)}=$ $2.48, \mathrm{p}=0.04$, for $\mathrm{TMS}_{(\mathrm{hMT}+/ \mathrm{N5})}, \mathrm{V} 5: \mathrm{t}_{(15)}=2.06, \mathrm{p}=0.04$, EVA: $\mathrm{t}_{(14)}=2.41, \mathrm{p}=0.03$, paired t-tests, Figure $5 B$ and $5 D$ ). Locally, the extracted beta values within the stimulated EVA ROI were negatively correlated with performance $(r=-0.55, p=0.04)$, while the relationship between the beta values within the stimulated V5 ROI and the performance was not significant $(r=0.31, p=$ 0.27).

We more specifically compared the neural effects of TMS when the visual stimulus was moving or static. The fMRI contrast $T M S_{(\mathrm{EVA})-\mathrm{Mov}}$ versus $T M S_{(\mathrm{EVA}) \text {-Stat }}$ revealed two significant clusters in EVA and hMT+/V5 (see Figure 4E for the activation map and 4F for the ROI analysis and Supplementary Table S5). The same sub-analysis for $\mathrm{TMS}_{(\mathrm{hMT}+\mathrm{N5})}$ did not show any significant clusters for both contrasts. 
A. $\mathrm{TMS}_{(\mathrm{EVA})}>$ noTMS contrast
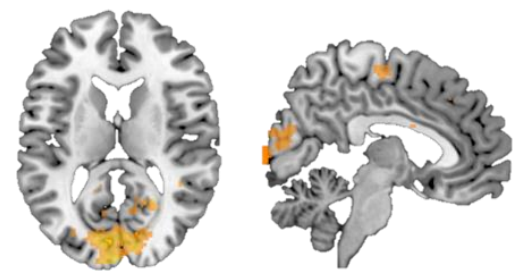

C. TMS (EVA) $_{\text {ROI analysis }}$

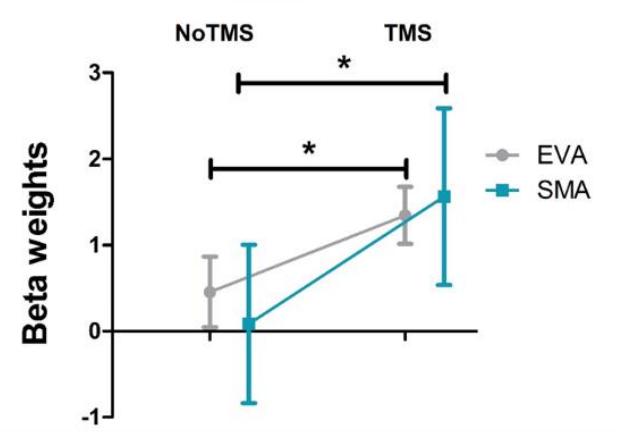

E. $\mathrm{TMS}_{(\mathrm{EVA})-\mathrm{Mov}}>\mathrm{TMS}_{(\mathrm{EVA})-\text { Stat }}$

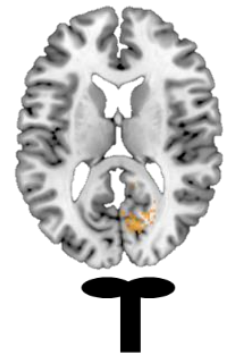

B. $\mathrm{TMS}_{(\mathrm{hMT}+/ \mathrm{VS})}>$ noTMS contrast

T values
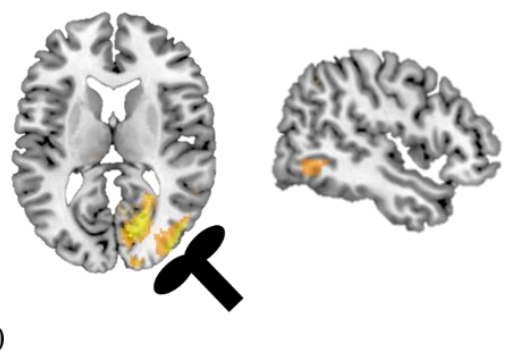

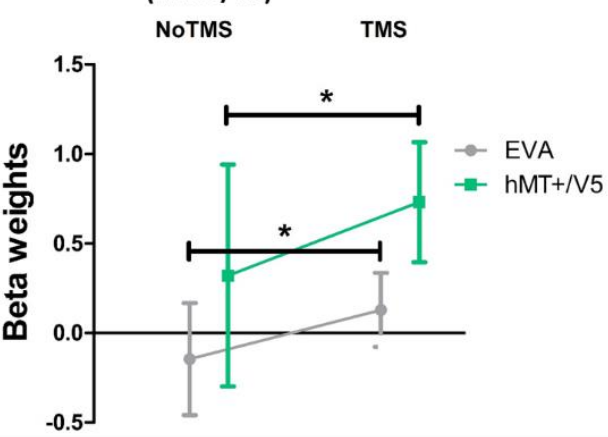

\section{F. TMS (EVA) $_{\text {ROI analysis }}$}

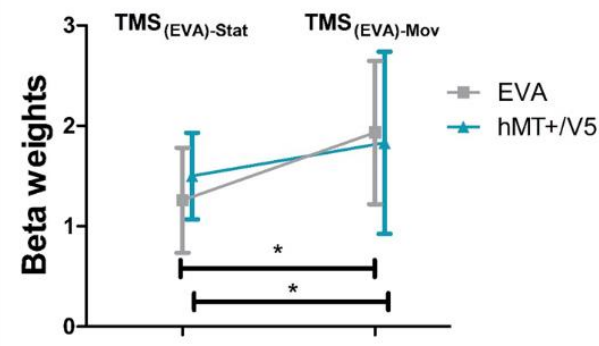

Figure 4: Task TMS: A: TMS (EVA) $>$ noTMS contrast; B: $\mathrm{TMS}_{(\mathrm{VS})}>$ noTMS contrast; $\mathrm{C}$ :

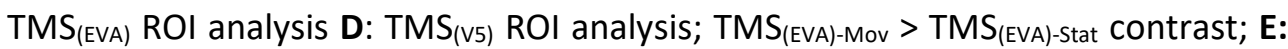
$\mathrm{TMS}_{(\mathrm{hMT}+/ \mathrm{NS})-\mathrm{Mov}}>\mathrm{TMS}_{(\mathrm{hMT}+/ \mathrm{N5}) \text {-Stat }} \mathrm{ROI}$ analysis; F: $\mathrm{TMS}_{(\mathrm{hMT}+/ \mathrm{NS})-\mathrm{Mov}}>\mathrm{TMS}_{(\mathrm{hMT}+/ \mathrm{NS}) \text {-Stat }}$ contrast and ROI analysis. EVA: primary visual cortex; hMT+/V5: Medio-temporal cortex; SMA: Supplementary Motor Area.

\subsubsection{Role of the visual processing stage:}

Since EVA and hMT+/V5 appear to be critical for motion discrimination in the early time window, we then investigated whether TMS targeting later feedforward signal integration in hMT+/V5 (TMS over hMT+/V5 130ms after stimulus onset, (Laycock et al., 2007)) or feedback processes to EVA (TMS over EVA 150 ms after stimulus onset (e.g., Wibral et al., 2009)) would similarly 
affect performances and BOLD signal, compared to the early time window. Figure $5 A$ shows the behavioural performance without TMS and the effects of the virtual lesion applied to EVA and $\mathrm{hMT+/V5}$ at the two different onsets after visual stimulus appearance. We first ran a rmANOVA with within-subjects factors Site (EVA/hMT+/V5) and TMS (noTMS/TMS/TMS late). It revealed a significant Site effect $\left(F_{(1,15)}=5.33, p=0.036\right)$, TMS effect $\left(F_{(2,30)}=20.7, p<0.001\right)$, as well as a significant Site by TMS interaction $\left(\mathrm{F}_{(2,30)}=4.25, \mathrm{p}=0.024\right)$. Within-group t-tests revealed that performances significantly dropped with $\operatorname{TMS}_{(\mathrm{EVA})}\left(\mathrm{t}_{(15)}=3.32, \mathrm{p}=0.005\right)$, but not with the later onset compared with noTMS (TMS $\left(\mathrm{EVAA}_{\mathrm{A}}: \mathrm{t}_{(15)}=1.44, \mathrm{p}=0.17\right)$. On $\mathrm{hMT}+/ \mathrm{V} 5$, both TMS onsets led to significant behavioral deterioration $\left(\mathrm{TMS}_{(\mathrm{hMT}+/ \mathrm{NS}):} \mathrm{t}_{(15)}=5.76, \mathrm{p}<0.001, \mathrm{TMS}_{(\mathrm{hMT}+/ \mathrm{N5}) \text {-late: }} \mathrm{t}_{(15)}=\right.$ $5.23, p<0.001)$

When taking motion awareness into account, the behavioural profiles (seen in Figure 5B upper panel for $\mathrm{TMS}_{(\mathrm{EVA})}$ and $5 \mathrm{~B}$ lower panel for $\mathrm{TMS}_{(\mathrm{hMT}+/ \mathrm{NS})}$ ) did not significantly differ (no site effect: $\left.F_{(1,30)}=1.02, p=0.5\right)$, but the link between awareness and performance appeared to vary across TMS condition as evidenced by the significant Rating by TMS conditions interaction $\left(F_{(6,6)}=4.54\right.$, $p=0.044)$. Visual inspection of the curves suggest that the interaction is mostly driven by the impairment induced by the early TMS onset in both areas. The curves related to the late onsets resembles the profiles obtained without TMS with a negative offset value, suggesting that the late TMS onsets did not particularly modify motion awareness.

The imaging data further indicated that the two TMS onset conditions in EVA produced a different pattern of activation with additional BOLD activity in the bilateral fronto-parietal network (i.e., bilateral FEF and PPC) for the late TMS onset (see Figure 5C and Supplementary Table S6). This was also suggested by the ROI analysis although the pairwise comparison was only significant in the PPC (early $\mathrm{TMS}_{(\mathrm{EVA})}$ versus late $\mathrm{TMS}_{(\mathrm{EVA})}$ in the PPC: $\mathrm{t}_{(11)}=2.65, p=0.03$; in the FEF: $\left.\mathrm{t}_{(10)}=1, \mathrm{p}=0.35\right)$. There was no significant cluster for $\mathrm{TMS}_{(\mathrm{hMT}+/ \mathrm{N5})}$. 
A. Behavioural performances

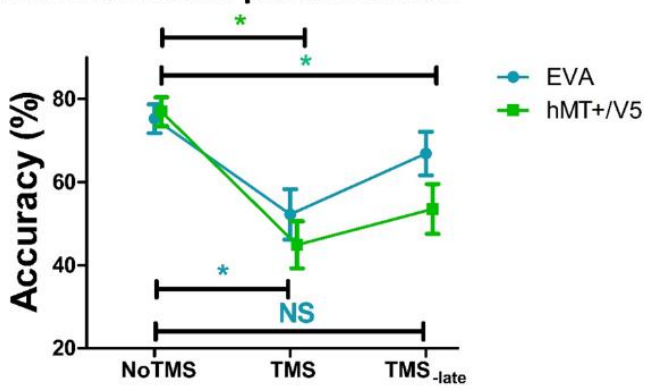

C. $\mathrm{TMS}_{(\mathrm{EVA}) \text {-late }}>\mathrm{TMS}_{(\mathrm{EVA})}$ contrast \& ROI analysis

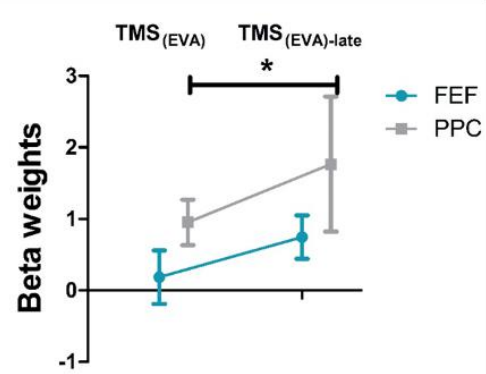

B. $\mathrm{TMS}_{(\mathrm{EVA})}$ and motion awareness

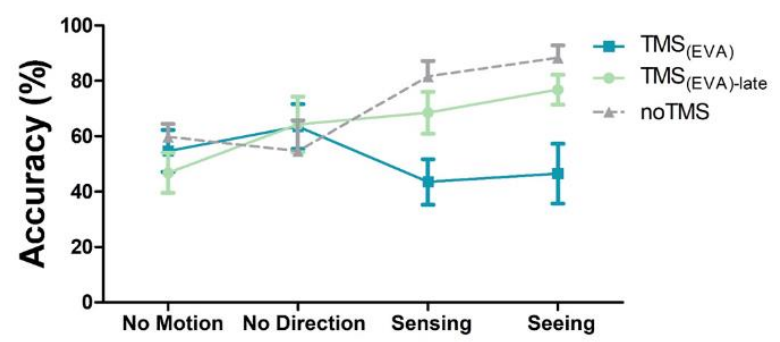

$\mathrm{TMS}_{(\mathrm{hMT}+/ \mathrm{VS})}$ and motion awareness

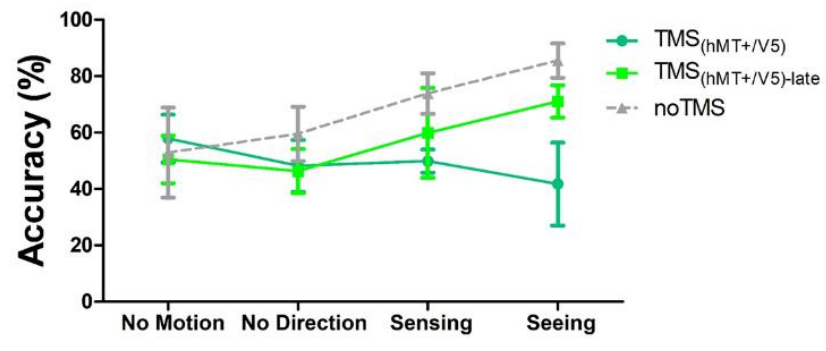

Figure 5A: Mean accuracy in motion discrimination with the two TMS onsets early (TMS) and late $\left(\mathrm{TMS}_{(\text {late) }}\right)$ over EVA and hMT+/V5; B: Relationship between behavioural accuracy and awareness of motion with $\mathrm{TMS}_{(\mathrm{EVA})}, \mathrm{TMS}_{(\mathrm{EVA}) \text {-late }}$ and noTMS (upper panel) and TMS $\mathrm{ThMT+/N5)}_{\text {, }} \mathrm{TMS}_{(\mathrm{hMT}+/ \mathrm{NS}) \text {-late }}$ and noTMS (lower panel); C: $\mathrm{TMS}_{(\mathrm{EVA}) \text {-late }}>\mathrm{TMS}_{(\mathrm{EVA})}$ contrast and ROI analysis.

\subsection{Multivariate analysis}

\subsubsection{TMS $(E V A)$ networks}

The ICA applied to the $\mathrm{TMS}_{(\mathrm{EVA})}$ data at rest revealed 16 components, among which 15 were considered as functional brain networks and two components considered as noise. The temporal regression analysis applied to the components' time courses showed that IC2, IC3 and IC11 were significantly modulated by $\mathrm{TMS}_{(\mathrm{EVA})}$ (Figure $6 \mathrm{~A}$ and see Supplementary Figure $\mathrm{S} 1$ for all functional brain networks and Supplementary Table S7 for the MNI coordinates). Those three networks encompassed the stimulated EVA area and the bilateral FEF and medial prefrontal cortex for IC3 and IC11. In line with the ROI analysis, IC2 and IC3 were significantly suppressed by TMS (IC2: $\left.\mathrm{t}_{(15)}=2.81, \mathrm{p}=0.013, \mathrm{IC} 3: \mathrm{t}_{(15)}=3.01, \mathrm{p}=0.011\right)$. In contrast IC11 increased with $\operatorname{TMS}\left(t_{(15)}=2.34, p=0.03\right.$, Figure $\left.6 \mathrm{C}\right)$. 
During motion discrimination, 16 components were identified, among which 13 were considered as functional brain networks (Figure 6B and see Supplementary Figure S2 and Supplementary Table S8). Visual inspection of these components suggested relatively focal networks and three of them showed significant TMS modulation (IC1, IC3 and IC14). These networks that only comprised the stimulated EVA area, were significantly up-regulated by TMS during motion discrimination (IC1: $\mathrm{t}_{(15)}=2.33, \mathrm{p}=0.05, \mathrm{IC} 3: \mathrm{t}_{(15)}=3.78, \mathrm{p}=0.002, \mathrm{IC} 14: \mathrm{t}_{(15)}=2.4$, $p=0.04$, Figure 6C).

\subsubsection{TMS $(h M T+/ N 5)$ networks}

Among the 14 (out of 16) components representing functional brain networks for $\mathrm{TMS}_{(\mathrm{V} 5)}$ at rest (see Supplementary Figure S3 and Supplementary Table S8), four were significantly modulated by TMS (IC1, IC3, IC5, IC16, Figure 6D). Those networks encompassed the stimulated right V5 area but also the Precuneus area (IC1, IC16), the intraparietal sulcus (IPS) and the right primary somatosensory cortex (S1) (IC5). In congruence with the ROI analysis, these networks were down-regulated with TMS (IC1: $\mathrm{t}_{(14)}=2.37, \mathrm{p}=0.03$, IC3: $\mathrm{t}_{(14)}=3.78, \mathrm{p}=0.002$, IC5: $\mathrm{t}_{(14)}=2.62, \mathrm{p}$ $=0.02, I_{C} 16: t_{(14)}=2.64, p=0.02$, Figure $\left.6 \mathrm{~F}\right)$. The same analysis during motion discrimination revealed two networks (IC5 and IC7) that were significantly modulated by TMS out of the 14 networks considered as functional brain networks (Figure 6E and see supplementary Figure S4 and Supplementary Table S9). Compared to $\mathrm{TMS}_{(\mathrm{EVA})}$, these networks were more diffused and were composed by the stimulated right hMT+/V5 area, the bilateral or contralateral left FEF (IC5 and IC7), the medial prefrontal cortex (IC5) and the superior parietal area (IC7). The network activity was significantly increased by TMS (IC5: $t_{(14)}=2.4 p=0.03, I C 7: t_{(14)}=2.6 p=0.02$, Figure $6 F)$. 
A

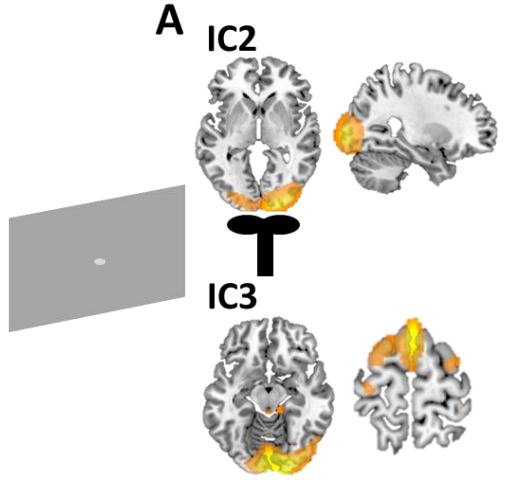

B IC1

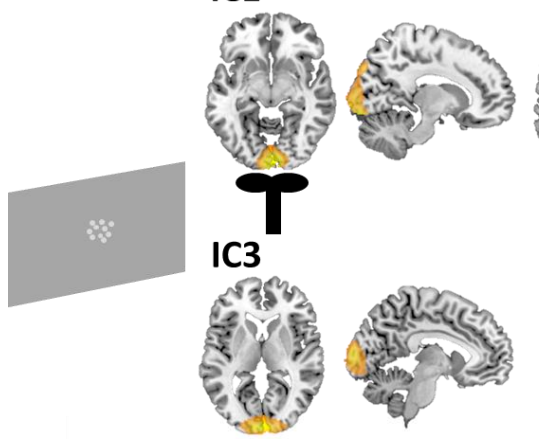

IC11

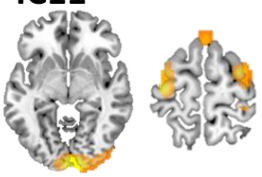

IC14

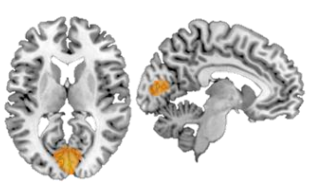

D IC1

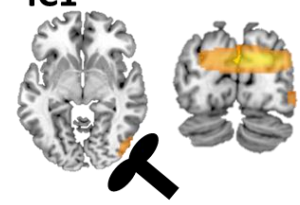

IC3

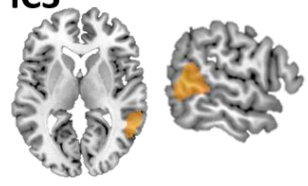

E IC5

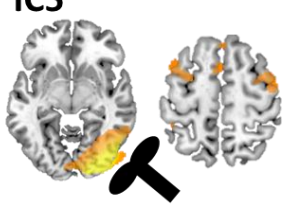

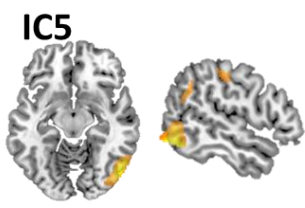

IC16

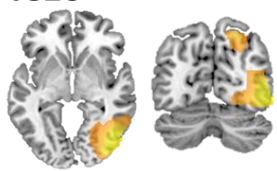

IC7
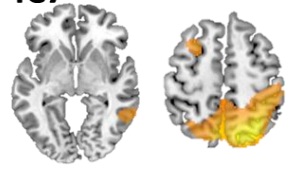

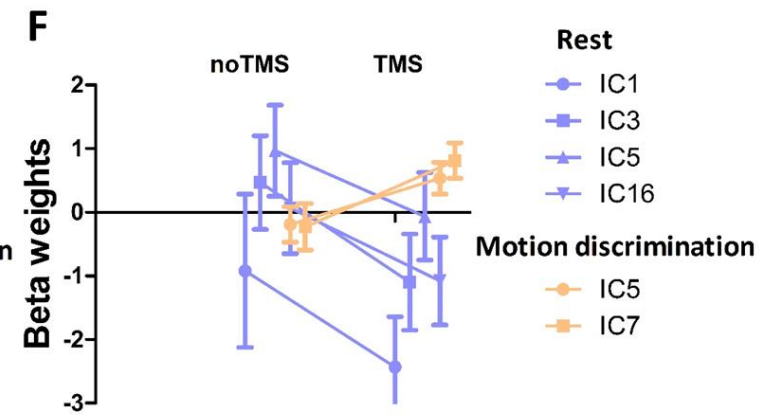

Figure 6A: TMS (EVA)-specific component networks that are modulated by TMS at

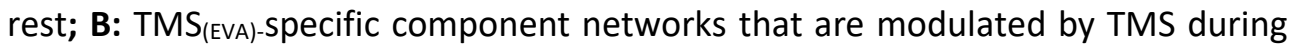
motion discrimination; C: Temporal regression analysis for the TMS(EVA) and noTMS

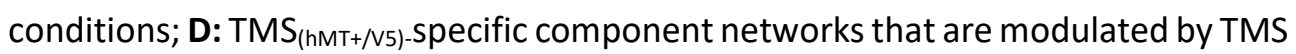

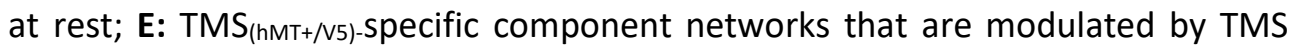
during motion discrimination; F: Temporal regression analysis for the $\mathrm{TMS}_{(\mathrm{hMT}+/ \mathrm{NS})}$ and noTMS conditions; IC: independent component. 


\section{Discussion}

This study used concurrent TMS - functional MRI applying a virtual lesion approach by means of short bursts of $10 \mathrm{~Hz}$ TMS delivered to either a low-level visual area (EVA) or a highly specialized, motion processing, visual area (hMT+/V5). We first confirmed targets causal engagement with a significant TMS time-dependent task impairment. Our findings also point towards a common TMS state-dependent neural mechanism and more subtly, towards distinct dynamical and topological TMS-induced networks properties depending on the TMS site and the visual processing stage, TMS was applied. Overall, the present results highlight the complexity of the TMS-induced virtual lesion effects and by extrapolation, suggest that the reorganization processes that take place after a permanent lesion might not only depend on the lesion site, but also on the functional connectivity and/or cognitive state of each individual patient.

\subsection{The neural effects of the virtual lesion differ with the brain state}

The present TMS intervention intended to reproduce what is currently called in the literature a virtual lesion (Pascual-Leone et al., 1999) (Silvanto and Muggleton, 2008) (Miniussi et al., 2010). In line with this concept, the TMS bursts resulted in a transient deterioration of performances of a left/right, global motion discrimination task. This was interpreted to reflect successful causal disruption of brain functioning and associated behaviour. At the neural level, the TMS-induced virtual lesion showed a clear state dependent component. A local loss of BOLD signal strength, as well as a decrease in TMS related network activity were found at rest for both $\mathrm{TMS}_{(\mathrm{EVA})}$ and

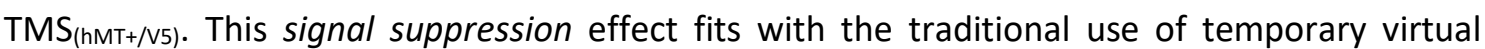
lesions in a healthy brain. Indeed, virtual lesions are classically associated with a temporary inactivation of a population of neurons (Sack et al., 2007) (Ruff et al., 2008) (Harris et al., 2008) (Mullin and Steeves, 2013) (Mason et al., 2014), thereby impairing behaviour (Burton et al., 
2009) (Ruzzoli et al., 2010) (Perini et al., 2012) (Schwarzkopf et al., 2011). Prior studies using concurrent or interleaved TMS and fMRI have described a localized decreased BOLD signal as being the neural signature of TMS-induced virtual lesion under different contexts (Sack et al., 2007) (Ruff et al., 2008) (Harris et al., 2008) (Mullin and Steeves, 2013) (Mason et al., 2014).

It is of note, that the same areas and networks identified as being depressed at rest were found to be over-activated during the motion direction discrimination task. This finding challenges the probably too simplistic neural suppression hypothesis mentioned above. Alternative hypotheses have been proposed to explain the TMS induced potential disturbances (e.g. Pascual-Leone et al., 1999) (Silvanto and Muggleton, 2008) (Vesia et al., 2008) (Preston and Newport, 2008) or paradoxical perceptual improvements (e.g., Nixon et al., 2004) (Ando 20066) (Silvanto and Pascual-Leone, 2008) (Tadin et al., 2011) (Duecker and Sack, 2013) (Solomon-Harris et al., 2016). Proponents of the random noise activity hypothesis state that TMS acts by inducing random neuronal activity that is unrelated to the ongoing activity (Ruzzoli et al., 2010) (Schwarzkopf et al., 2011). Several accounts suggest that functionally distinct neural populations in the stimulated region can be differentially activated by TMS: neurons that are less active (because they are less relevant to the task) become activated by TMS, therefore adding noise and generating a behavioural disturbance (Cowey et al., 2006) (Walsh and PascualLeone, 2003) (Bancroft et al., 2014) (Silvanto and Muggleton, 2008). In our case, the local overactivation induced by the TMS bursts might represent the activity of groups of neurons preferentially coding for off-axis directions from the ones to discriminate on the screen, worsening the signal-to-noise ratio of the task. This would be the case in both EVA and hMT+/V5.

Why and how these opposing mechanisms (deactivation and over-activation) co-exist and operate potentially in parallel, is an active area of research (see e.g., Wu et al., 2019). Other groups have found behavioural responses to TMS to be context or state-dependent as well (Campana et al., 2002) (Cattaneo et al., 2008) (Cattaneo et al., 2010) (de Graaf et al., 2014) 
(Sandrini et al., 2011) (see Silvanto and Cattaneo, 2017 for a review). However, there are only few imaging studies reporting state-dependent effects of TMS on the BOLD signal (e.g., Bestmann et al., 2008) (Blankenburg et al., 2010) (Leitão et al., 2015). The present study provides the first evidence of a state-dependency of TMS-induced virtual lesions over EVA and hMT+/V5, locally on the targeted region and via functional coupling at the network level when comparing a resting versus an active state. Moreover, during the visual task, TMS(EVA) produced two distinct activation maps associated with moving or static visual stimuli. This could represent an anatomical substrate for contextual modulation of TMS effects in EVA. We can speculate that the early contextual integration in EVA allows a functional routing of information towards the highly specialized EVA-hMT+/V5 pathway, as evidenced by the over-activation in these two areas only with moving stimuli. This was not the case for $\mathrm{TMS}_{(\mathrm{hMT}+/ \mathrm{NS})}$ for which TMS produced a similar BOLD increase in EVA and hMT+/V5 irrespective to the visual context.

\subsection{Virtual lesion effects also differ throughout visual processing}

On both stimulated areas, the TMS bursts were sent at two different time points during motion discrimination in order to interfere specifically with different recurrent operations within the EVA-hMT+/V5 network. The combination of this unique experimental setup and task design allowed to probe the neural correlates of the TMS induced virtual lesion specific to a visual processing stage and to the associated behavioural perturbation, providing new insights into the dynamical properties of visual network adaptations compared to lesion studies (e.g.g._. Pasternak and Merigan,_1994) (Das et al., 2012) (see Figure 7 for a summary of the TMS conditions and the associated behavioural perturbations). 


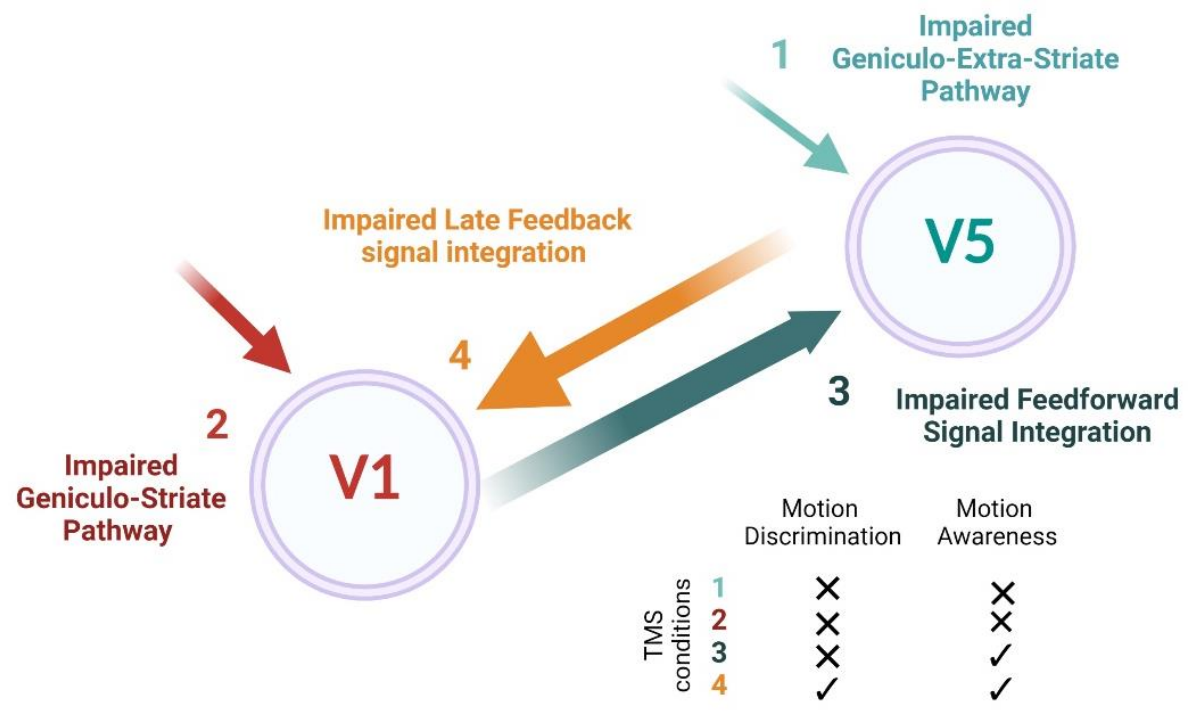

Figure 7: TMS induced "lesion" models and behavioural effects on visual perception. Digits 1 to 4 represent the different visual processing stages at which TMS-induced virtual lesion was applied. 1 corresponds to TMS applied to hMT+/V5, $\approx 30 \mathrm{~ms}$ after visual stimulus onset, impairing the geniculo-extra-striate pathway; 2 corresponds to TMS applied over EVA $\approx 60 \mathrm{~ms}$ after visual stimulus onset, impairing the main geniculo-striate pathway; 3 corresponds to TMS over $h M T+/ V 5 \approx 130$ ms after visual stimulus onset, impairing late feedforward signal integration in $h M T+/ V 5 ; 4$ corresponds to TMS over EVA applied $\approx 150 \mathrm{~ms}$ after stimulus onset impairing late feedback signal integration in EVA. The table on the bottom right of the figure summarizes the TMS-induced virtual lesion effects on motion discrimination performances and on motion awareness when applied at these four different processing stages.

When the TMS bursts were applied over EVA at the time point where the visual inputs via the main geniculo-striate pathway reach EVA (i.e., $60 \mathrm{~ms}$ after stimulus onset), motion direction discrimination was considerably disturbed. Motion awareness was also perturbed in the sense that a substantial number of moving stimuli were perceived as being static. Exploring the link between motion awareness and performance, it appeared that aware perception was significantly reduced (i.e., for the moving trials that were judged as "perceived", motion direction was not correctly guessed), but unaware motion perception was not impaired, suggesting that one possible candidate mediating the distorted, but residual motion direction discrimination capacity might be the direct geniculo-extra-striate pathway (Abed Rabbo et al., 2015) (Bridge et al., 2008). This pathway has been shown to be critical in the detection of fast and unconscious motion typically in stroke patients with EVA lesion (phenomenon called 
Blindsight) (Weiskrantz et al., 1974) (Ajina et al., 2015) (Leh et al., 2006). When the bursts were applied over EVA at the latencies matching the late re-entrant inputs (i.e., 150ms after visual stimulus onset), performances were slightly lower, but not significantly different from no TMS. Moreover, motion perception was not altered, both aware and unaware performances were not different from the no TMS condition. Interestingly, both TMS $(\mathrm{EVA})$ conditions induced an overactivation of local EVA circuits, but only the $\mathrm{TMS}_{(\mathrm{EVA}) \text {-late }}$ bursts were associated with a supplementary fronto-parietal activity, which might be explained by the additional time given to the visual signals to reach higher brain regions. Congruently, awake intracortical stimulation of the parietal-premotor network has been shown to induce motion awareness (e.g.g. Desmurget and Sirigu, 2009).

When the direct geniculo-extra-striate pathway was perturbed by TMS applied over $\mathrm{hMT+/V5} 30 \mathrm{~ms}$ after stimulus onset, performances and more precisely aware performances were altered. The preserved unaware motion perception could potentially be explained by a very early activity recorded in hMT+/V5 around the stimulus onset period (Beckers and Hömberg, 1992) (Raiguel et al., 1999) (A. A. L. d'Alfonso et al., 2002). When hMT+/V5 was stimulated at a later time-window $(\approx 130 \mathrm{~ms})$, global performances remained significantly worse than for the no TMS condition. Performances were similarly affected along the subjective scale of motion awareness, suggesting that motor awareness was not necessarily affected. This findings confirm that the integration and recurrent processing of the fast re-entrant signals from hMT+/V5 with the feedforward output signals from EVA supports motion awareness (e.g, Romei et $\underline{\text { al }} \underline{L}_{\llcorner} \underline{2} \underline{0} \underline{1} \underline{6}$. Associated with the generalized motion discrimination impairment, the imaging data showed an over-activation in the stimulated $\mathrm{hMT}+/ \mathrm{V} 5$ area and in EVA for both TMS onsets, suggesting that not only the local stimulated area was perturbed, but the entire EVA-hMT+/V5 pathway involved in motion discrimination. 


\subsection{Remote effects are different depending on virtual lesion site}

Our data provide evidence for distinct network effects between the two TMS sites, especially during the task. We found that the $\mathrm{TMS}_{(\mathrm{hMT}+\mathrm{NS})}$ networks were spatially more distributed, including additional associative areas, such as the frontal eye field (FEF), the posterior parietal cortex (PPC) or the medial prefrontal cortex (mPFC). In comparison, the independent components forming the TMS-related networks in response to $\mathrm{TMS}_{(\mathrm{EVA})}$ were restricted to the stimulated EVA and highly correlated among themselves (data not shown here). It is possible that these spatially restricted and temporally correlated $\mathrm{TMS}_{(\mathrm{EVA})}$ networks enable flexible redistribution of network activity, to maintain an orchestrated network stability despite various internal and external perturbations (see e.g., Wu et al., 2019). This acute neuronal adaptation seen for $\mathrm{TMS}_{(\mathrm{EVA}) \text {-late }}$ for which the strongly diminished network activity was associated with preserved visual performances. In contrast, the existence of the scattered functional $\mathrm{TMS}_{(\mathrm{hMT}+/ \mathrm{N} 5)}$ networks might reflect task-irrelevant activity that is distributed over higher visual brain regions (FEF, PPC or mPFC). This activity, found for both $\mathrm{hMT}+\mathrm{V} 5$ onsets, might prevent the functionally inter-connected areas to compensate/re-balance network activity, explaining the impaired performances found for both onsets. This difference in network adaptation between $\mathrm{TMS}_{(\mathrm{EVA})}$ and $\mathrm{TMS}_{(\mathrm{hMT}+\mathrm{NS})}$ is in congruence with a modelling study, showing that brain hubs, where activity is integrated and further distributed (like EVA in our case) operate in a slower regime and appear to be functionally less affected by focal perturbations (Gollo et al., 2017). In contrast, perturbations of peripheral regions or more associative areas (e.g., hMT+/V5) that are characterized by faster activity, might have greater impact on acute network activity. Lesion studies also provided evidence that lesions to the homologue of EVA versus hMT+/V5 in behaving cats differently impact on relearning of motion discrimination (Das et al., 2012). It was shown that lesions to EVA impair performances, but visual training on a global motion task can improve processing and sensitivity for multiple visual stimulus types. However, when hMT+/V5 cortex is damaged, the same training generalizes less. 


\subsection{Limitations}

The present results highlight the complexity of TMS induced virtual lesion effects, but it is important to acknowledge that the BOLD signal is related to changes in brain blood flow and blood oxygenation, tied to underlying neuronal activity through neurovascular coupling (Hillman, 2014). As such, it reflects a mixture of synaptic signals (i.e., peri- and postsynaptic processes) rather than firing rate (i.e., action potentials) in the neuron populations from which the signal is extracted. Consequently, we cannot strictly conclude about the specific contribution of excitatory vs. inhibitory circuitry in the positive and negative BOLD signals found when TMS is applied during visual processing or at rest respectively (Logothetis and Pfeuffer, 2004) (Logothetis, 2008). Further multimodal imaging studies are needed to infer on the role of the excitation/inhibition balance on neuronal network organization and information processing, especially in the context of brain lesions.

\subsection{Conclusion}

Despite growing interest and extensive mathematical/computational modelling contributions, the causal mechanisms underlying neural network dynamics, especially after a lesion, remain elusive. Concurrent TMS-fMRI coupling has been used as a tool to probe neural mechanisms underlying functional reorganization of whole-brain dynamics using "virtual-lesion" approaches. Here, we provide behavioural and imaging evidence that the neural effects of TMSinduced virtual lesions are more complex than initially proposed with strong state-dependent responses at the regional and network level. Additionally, we demonstrate that selective, focal virtual lesions can result in distinct large-scale dis-regulations in visual network activity, depending on which hierarchical level is perturbed and on which visual processing stage is targeted. TMS signals are differently integrated and propagated when targeting processing in 
bioRxiv preprint doi: https://doi.org/10.1101/2022.03.03.482512; this version posted March 4, 2022. The copyright holder for this preprint (which was not certified by peer review) is the author/funder. All rights reserved. No reuse allowed without permission.

early visual areas or in a higher-level visual area, such as hMT+/V5. These findings motivate the use of TMS-fMRI coupling as a complementary tool to assess 'disconnectomics' and their network and behavioural effects after brain lesions, such as in stroke (Egger et al., 2021). This technique could be leveraged to precisely map how a local perturbation propagates to largescale behavioural deficits by comparing the neural impact of TMS-induced virtual lesion during different active cognitive processes. 


\section{References}

Abed Rabbo F, Koch G, Lefèvre C, Seizeur R. 2015. Direct geniculo-extrastriate pathways: a review of the literature. Surg Radiol Anat SRA 37:891-899. doi:10.1007/s00276-0151450-7

Ajina S, Pestilli F, Rokem A, Kennard C, Bridge H. 2015. Human blindsight is mediated by an intact geniculo-extrastriate pathway. eLife 4:e08935. doi:10.7554/eLife.08935

Alexander B, Laycock R, Crewther DP, Crewther SG. 2018. An fMRI-Neuronavigated Chronometric TMS Investigation of V5 and Intraparietal Cortex in Motion Driven Attention. Front Hum Neurosci 11. doi:10.3389/fnhum.2017.00638

Allen CPG, Sumner P, Chambers CD. 2014. The Timing and Neuroanatomy of Conscious Vision as Revealed by TMS-induced Blindsight. J Cogn Neurosci 26:1507-1518. doi:10.1162/jocn_a_00557

Amassian VE, Cracco RQ, Maccabee PJ, Cracco JB, Rudell A, Eberle L. 1989. Suppression of visual perception by magnetic coil stimulation of human occipital cortex. Electroencephalogr Clin Neurophysiol Potentials Sect 74:458-462. doi:10.1016/01685597(89)90036-1

Andersson JLR, Hutton C, Ashburner J, Turner R, Friston K. 2001. Modeling Geometric Deformations in EPI Time Series. Neurolmage 13:903-919. doi:10.1006/nimg.2001.0746

Andoh J, Artiges E, Pallier C, Rivière D, Mangin JF, Cachia A, Plaze M, Paillère-Martinot ML, Martinot JL. 2006. Modulation of language areas with functional MR image-guided magnetic stimulation. Neurolmage 29:619-627. doi:10.1016/j.neuroimage.2005.07.029

Ashburner J, Friston KJ. 2005. Unified segmentation. Neurolmage 26:839-851. doi:10.1016/j.neuroimage.2005.02.018

Bancroft TD, Hogeveen J, Hockley WE, Servos P. 2014. TMS-induced neural noise in sensory cortex interferes with short-term memory storage in prefrontal cortex. Front Comput Neurosci 8. doi:10.3389/fncom.2014.00023

Bassett DS, Bullmore ET. 2009. Human brain networks in health and disease. Curr Opin Neurol 22:340-347. doi:10.1097/WCO.0b013e32832d93dd

Beckers G, Homberg V. 1992. Cerebral Visual Motion Blindness: Transitory Akinetopsia Induced by Transcranial Magnetic Stimulation of Human Area V5. Proc Biol Sci 249:173-178.

Beckers G, Hömberg V. 1992. Cerebral visual motion blindness: transitory akinetopsia induced by transcranial magnetic stimulation of human area V5. Proc Biol Sci 249:173-178. doi:10.1098/rspb.1992.0100

Bell AJ, Sejnowski TJ. 1995. An information-maximization approach to blind separation and blind deconvolution. Neural Comput 7:1129-1159. doi:10.1162/neco.1995.7.6.1129

Bestmann S. 2008. Mapping Causal Interregional Influences With Concurrent TMS-fMRI PubMed. Exp Brain Res.

Bestmann S, Swayne O, Blankenburg F, Ruff CC, Haggard P, Weiskopf N, Josephs O, Driver J, Rothwell JC, Ward NS. 2008. Dorsal Premotor Cortex Exerts State-Dependent Causal Influences on Activity in Contralateral Primary Motor and Dorsal Premotor Cortex. Cereb Cortex 18:1281-1291. doi:10.1093/cercor/bhm159

Bieri O, Scheffler K. 2013. Fundamentals of balanced steady state free precession MRI. J Magn Reson Imaging 38:2-11. doi:https://doi.org/10.1002/jmri.24163

Blankenburg F, Ruff CC, Bestmann S, Bjoertomt O, Josephs O, Deichmann R, Driver J. 2010. Studying the Role of Human Parietal Cortex in Visuospatial Attention with Concurrent TMS-fMRI. Cereb Cortex 20:2702-2711. doi:10.1093/cercor/bhq015

Brett M, Anton JL, Valabrgue R, Poline J-B. 2002. Region of interest analysis using an SPM toolbox. Presented at the 8th International Conference on Functional Mapping of the Human Brain, June 2-6, 2002, Sendai, Japan. Neuroimage 13:210-217. 
Bridge $\mathrm{H}$, Thomas $\mathrm{O}$, Jbabdi S, Cowey A. 2008. Changes in connectivity after visual cortical brain damage underlie altered visual function. Brain J Neurol 131:1433-1444. doi:10.1093/brain/awn063

Bullmore E, Sporns O. 2012. The economy of brain network organization. Nat Rev Neurosci 13:336-349. doi:10.1038/nrn3214

Burton B, Hok V, Save E, Poucet B. 2009. Lesion of the ventral and intermediate hippocampus abolishes anticipatory activity in the medial prefrontal cortex of the rat. Behav Brain Res 199:222-234. doi:10.1016/j.bbr.2008.11.045

Calhoun VD, Adali T, Pearlson GD, Pekar JJ. 2001. A method for making group inferences from functional MRI data using independent component analysis. Hum Brain Mapp 14:140151. doi:10.1002/hbm.1048

Campana G, Cowey A, Walsh V. 2002. Priming of motion direction and area V5/MT: A test of perceptual memory. Cereb Cortex 12:663-669. doi:10.1093/cercor/12.6.663

Cattaneo L, Sandrini M, Schwarzbach J. 2010. State-Dependent TMS Reveals a Hierarchical Representation of Observed Acts in the Temporal, Parietal, and Premotor Cortices. Cereb Cortex 20:2252-2258. doi:10.1093/cercor/bhp291

Cattaneo Z, Rota F, Vecchi T, Silvanto J. 2008. Using state-dependency of transcranial magnetic stimulation (TMS) to investigate letter selectivity in the left posterior parietal cortex: a comparison of TMS-priming and TMS-adaptation paradigms. Eur J Neurosci 28:19241929. doi:10.1111/j.1460-9568.2008.06466.x

Cocchi L, Sale MV, L Gollo L, Bell PT, Nguyen VT, Zalesky A, Breakspear M, Mattingley JB. 2016. A hierarchy of timescales explains distinct effects of local inhibition of primary visual cortex and frontal eye fields. elife 5:e15252. doi:10.7554/eLife.15252

Cowey A, Campana G, Walsh V, Vaina LM. 2006. The role of human extra-striate visual areas V5/MT and V2/V3 in the perception of the direction of global motion: a transcranial magnetic stimulation study. Exp Brain Res 171:558-562. doi:10.1007/s00221-0060479-6

d'Alfonso AA, van Honk J, Schutter DJ, Caffé AR, Postma A, de Haan EH. 2002. Spatial and temporal characteristics of visual motion perception involving V5 visual cortex. Neurol Res 24:266-270. doi:10.1179/016164102101199891

d'Alfonso AAL, Honk J van, Schutter DJLG, Caffé AR, Postma A, Haan EHF de. 2002. Spatial and temporal characteristics of visual motion perception involving V5 visual cortex. Neurol Res 24:266-270. doi:10.1179/016164102101199891

Das A, DeMagistris M, Huxlin KR. 2012. Different Properties of Visual Relearning after Damage to Early Versus Higher-Level Visual Cortical Areas. J Neurosci 32:5414-5425. doi:10.1523/JNEUROSCI.0316-12.2012

de Graaf TA, Koivisto M, Jacobs C, Sack AT. 2014. The chronometry of visual perception: review of occipital TMS masking studies. Neurosci Biobehav Rev 45:295-304. doi:10.1016/j.neubiorev.2014.06.017

Desmurget M, Sirigu A. 2009. A parietal-premotor network for movement intention and motor awareness. Trends Cogn Sci 13:411-419. doi:10.1016/j.tics.2009.08.001

Duecker F, Sack AT. 2013. Pre-stimulus sham TMS facilitates target detection. PloS One 8:e57765. doi:10.1371/journal.pone.0057765

Egger P, Evangelista GG, Koch PJ, Park C-H, Levin-Gleba L, Girard G, Beanato E, Lee J, Choirat C, Guggisberg AG, Kim Y-H, Hummel FC. 2021. Disconnectomics of the Rich Club Impacts Motor Recovery After Stroke. Stroke STROKEAHA120031541. doi:10.1161/STROKEAHA.120.031541

Eldaief MC, Halko MA, Buckner RL, Pascual-Leone A. 2011. Transcranial magnetic stimulation modulates the brain's intrinsic activity in a frequency-dependent manner. Proc Natl Acad Sci U S A 108:21229-21234. doi:10.1073/pnas.1113103109

Fornito A, Zalesky A, Breakspear M. 2015. The connectomics of brain disorders. Nat Rev Neurosci 16:159-172. doi:10.1038/nrn3901 
Fox MD, Halko MA, Eldaief MC, Pascual-Leone A. 2012. Measuring and manipulating brain connectivity with resting state functional connectivity magnetic resonance imaging (fcMRI) and transcranial magnetic stimulation (TMS). Neurolmage 62:2232-2243. doi:10.1016/j.neuroimage.2012.03.035

Gilaie-Dotan S. 2016. Visual motion serves but is not under the purview of the dorsal pathway. Neuropsychologia 89:378-392. doi:10.1016/j.neuropsychologia.2016.07.018

Gollo LL, Roberts JA, Cocchi L. 2017. Mapping how local perturbations influence systems-level brain dynamics. Neurolmage 160:97-112. doi:10.1016/j.neuroimage.2017.01.057

Grasso PA, Làdavas E, Bertini C, Caltabiano S, Thut G, Morand S. 2018. Decoupling of Early V5 Motion Processing from Visual Awareness: A Matter of Velocity as Revealed by Transcranial Magnetic Stimulation. J Cogn Neurosci 30:1517-1531. doi:10.1162/jocn_a_01298

Grefkes C, Nowak DA, Wang LE, Dafotakis M, Eickhoff SB, Fink GR. 2010. Modulating cortical connectivity in stroke patients by rTMS assessed with $\mathrm{fMRI}$ and dynamic causal modeling. Neurolmage 50:233-242. doi:10.1016/j.neuroimage.2009.12.029

Haenny PE, Schiller PH. 1988. State dependent activity in monkey visual cortex. Exp Brain Res 69:225-244. doi:10.1007/BF00247569

Harris JA, Clifford CWG, Miniussi C. 2008. The functional effect of transcranial magnetic stimulation: signal suppression or neural noise generation? J Cogn Neurosci 20:734740. doi:10.1162/jocn.2008.20048

Hillman EMC. 2014. Coupling Mechanism and Significance of the BOLD Signal: A Status Report. Annu Rev Neurosci 37:161-181. doi:10.1146/annurev-neuro-071013-014111

Himberg J, Hyvärinen A, Esposito F. 2004. Validating the independent components of neuroimaging time series via clustering and visualization. Neurolmage 22:1214-1222. doi:10.1016/j.neuroimage.2004.03.027

Hochstein S, Ahissar M. 2002. View from the Top: Hierarchies and Reverse Hierarchies in the Visual System. Neuron 36:791-804. doi:10.1016/S0896-6273(02)01091-7

Jung J, Bungert A, Bowtell R, Jackson SR. 2020a. Modulating Brain Networks With Transcranial Magnetic Stimulation Over the Primary Motor Cortex: A Concurrent TMS/fMRI Study. Front Hum Neurosci 14. doi:10.3389/fnhum.2020.00031

Jung J, Bungert A, Bowtell R, Jackson SR. 2020b. Modulating Brain Networks With Transcranial Magnetic Stimulation Over the Primary Motor Cortex: A Concurrent TMS/fMRI Study. Front Hum Neurosci 14. doi:10.3389/fnhum.2020.00031

Kammer T, Puls K, Strasburger H, Hill NJ, Wichmann FA. 2005. Transcranial magnetic stimulation in the visual system. I. The psychophysics of visual suppression. Exp Brain Res 160:118-128. doi:10.1007/s00221-004-1991-1

Koivisto M, Leino K, Pekkarinen A, Karttunen J, Railo H, Hurme M. 2021. Transcranial magnetic stimulation (TMS)-induced Blindsight of Orientation is Degraded Conscious Vision. Neuroscience. doi:10.1016/j.neuroscience.2021.08.025

Koivisto M, Mäntylä T, Silvanto J. 2010. The role of early visual cortex (V1/V2) in conscious and unconscious visual perception. Neurolmage 51:828-834. doi:10.1016/j.neuroimage.2010.02.042

Lamme VA. 2001. Blindsight: the role of feedforward and feedback corticocortical connections. Acta Psychol (Amst) 107:209-228. doi:10.1016/s0001-6918(01)00020-8

Lamme VA, Roelfsema PR. 2000. The distinct modes of vision offered by feedforward and recurrent processing. Trends Neurosci 23:571-579. doi:10.1016/s0166-2236(00)01657$x$

Lamme VA, Supèr H, Spekreijse H. 1998. Feedforward, horizontal, and feedback processing in the visual cortex. Curr Opin Neurobiol 8:529-535. doi:10.1016/S0959-4388(98)80042-1

Laycock R, Crewther DP, Fitzgerald PB, Crewther SG. 2007a. Evidence for Fast Signals and Later Processing in Human V1/V2 and V5/MT+: A TMS Study of Motion Perception. J Neurophysiol 98:1253-1262. doi:10.1152/jn.00416.2007 
Laycock R, Crewther DP, Fitzgerald PB, Crewther SG. 2007b. Evidence for fast signals and later processing in human V1/V2 and V5/MT+: A TMS study of motion perception. $J$ Neurophysiol 98:1253-1262. doi:10.1152/jn.00416.2007

Leh SE, Johansen-Berg H, Ptito A. 2006. Unconscious vision: new insights into the neuronal correlate of blindsight using diffusion tractography. Brain 129:1822-1832. doi:10.1093/brain/awl111

Leitão J, Thielscher A, Tünnerhoff J, Noppeney U. 2015. Concurrent TMS-fMRI Reveals Interactions between Dorsal and Ventral Attentional Systems. J Neurosci 35:1144511457. doi:10.1523/JNEUROSCI.0939-15.2015

Logothetis NK. 2008. What we can do and what we cannot do with fMRI. Nature 453:869-878. doi:10.1038/nature06976

Logothetis NK, Pfeuffer J. 2004. On the nature of the BOLD fMRI contrast mechanism. Magn Reson Imaging, Proceedings of the International School on Magnetic Resonance and Brain Function 22:1517-1531. doi:10.1016/j.mri.2004.10.018

Mason RA, Prat CS, Just MA. 2014. Neurocognitive Brain Response to Transient Impairment of Wernicke's Area. Cereb Cortex N Y NY 24:1474-1484. doi:10.1093/cercor/bhs423

Miniussi C, Ruzzoli M, Walsh V. 2010. The mechanism of transcranial magnetic stimulation in cognition. Cortex J Devoted Study Nerv Syst Behav 46:128-130. doi:10.1016/j.cortex.2009.03.004

Mullin CR, Steeves JKE. 2013. Consecutive TMS-fMRI Reveals an Inverse Relationship in BOLD Signal between Object and Scene Processing. J Neurosci 33:19243-19249. doi:10.1523/JNEUROSCI.2537-13.2013

Navarro de Lara LI, Tik M, Woletz M, Frass-Kriegl R, Moser E, Laistler E, Windischberger C. 2017. High-sensitivity TMS/fMRI of the Human Motor Cortex Using a Dedicated Multichannel MR Coil. Neurolmage 150:262-269. doi:10.1016/j.neuroimage.2017.02.062

Navarro de Lara LI, Windischberger C, Kuehne A, Woletz M, Sieg J, Bestmann S, Weiskopf N, Strasser B, Moser E, Laistler E. 2015. A novel coil array for combined TMS/fMRI experiments at 3 T. Magn Reson Med 74:1492-1501. doi:10.1002/mrm.25535

Nixon P, Lazarova J, Hodinott-Hill I, Gough P, Passingham R. 2004. The Inferior Frontal Gyrus and Phonological Processing: An Investigation using rTMS. J Cogn Neurosci 16:289300. doi:10.1162/089892904322984571

Ozdemir RA, Tadayon E, Boucher P, Momi D, Karakhanyan KA, Fox MD, Halko MA, PascualLeone A, Shafi MM, Santarnecchi E. 2020. Individualized perturbation of the human connectome reveals reproducible biomarkers of network dynamics relevant to cognition. Proc Natl Acad Sci 117:8115-8125. doi:10.1073/pnas.1911240117

Papo D, Buldú JM, Boccaletti S, Bullmore ET. 2014. Complex network theory and the brain. Philos Trans R Soc B Biol Sci 369:20130520. doi:10.1098/rstb.2013.0520

Pascual-Leone A, Bartres-Faz D, Keenan JP. 1999. Transcranial magnetic stimulation: studying the brain-behaviour relationship by induction of "virtual lesions." Philos Trans $R$ Soc Lond B Biol Sci 354:1229-1238. doi:10.1098/rstb.1999.0476

Pasternak T, Merigan WH. 1994. Motion Perception following Lesions of the Superior Temporal Sulcus in the Monkey. Cereb Cortex 4:247-259. doi:10.1093/cercor/4.3.247

Peña-Gómez C, Sala-Lonch R, Junqué C, Clemente IC, Vidal D, Bargalló N, Falcón C, Valls-Solé J, Pascual-Leone Á, Bartrés-Faz D. 2012. Modulation of large-scale brain networks by transcranial direct current stimulation evidenced by resting-state functional MRI. Brain Stimulat 5:252-263. doi:10.1016/j.brs.2011.08.006

Perini F, Cattaneo L, Carrasco M, Schwarzbach JV. 2012. Occipital Transcranial Magnetic Stimulation Has an Activity-Dependent Suppressive Effect. J Neurosci 32:12361-12365. doi:10.1523/JNEUROSCI.5864-11.2012

Peters JC, Reithler J, Graaf TA de, Schuhmann T, Goebel R, Sack AT. 2020. Concurrent human TMS-EEG-fMRI enables monitoring of oscillatory brain state-dependent gating of 
cortico-subcortical network activity. Commun Biol 3:1-11. doi:10.1038/s42003-0200764-0

Petitet P, Noonan MP, Bridge H, O'Reilly JX, O'Shea J. 2015. Testing the inter-hemispheric competition account of visual extinction with combined TMS/fMRI. Neuropsychologia 74:63-73. doi:10.1016/j.neuropsychologia.2015.04.021

Piasini E, Soltuzu L, Muratore P, Caramellino R, Vinken K, Op de Beeck H, Balasubramanian V, Zoccolan D. 2021. Temporal stability of stimulus representation increases along rodent visual cortical hierarchies. Nat Commun 12:4448. doi:10.1038/s41467-021-24456-3

Preston C, Newport R. 2008. Misattribution of movement agency following right parietal TMS. Soc Cogn Affect Neurosci 3:26-32. doi:10.1093/scan/nsm036

Rademaker RL, van de Ven VG, Tong F, Sack AT. 2017. The impact of early visual cortex transcranial magnetic stimulation on visual working memory precision and guess rate. PLOS ONE 12. doi:10.1371/journal.pone.0175230

Raiguel SE, Xiao D-K, Marcar VL, Orban GA. 1999. Response Latency of Macaque Area MT/V5 Neurons and Its Relationship to Stimulus Parameters. J Neurophysiol 82:1944-1956. doi:10.1152/jn.1999.82.4.1944

Ricci R, Salatino A, Li X, Funk A, Logan S, Mu Q, Johnson K, Bohning D, George M. 2012. Imaging the neural mechanisms of TMS neglect-like bias in healthy volunteers with the interleaved TMS/fMRI technique: preliminary evidence. Front Hum Neurosci 6. doi:10.3389/fnhum.2012.00326

Romei V, Chiappini E, Hibbard PB, Avenanti A. 2016. Empowering Reentrant Projections from V5 to V1 Boosts Sensitivity to Motion. Curr Biol 26:2155-2160. doi:10.1016/j.cub.2016.06.009

Rossi S, Antal A, Bestmann S, Bikson M, Brewer C, Brockmöller J, Carpenter LL, Cincotta M, Chen R, Daskalakis JD, Di Lazzaro V, Fox MD, George MS, Gilbert D, Kimiskidis VK, Koch G, Ilmoniemi RJ, Lefaucheur JP, Leocani L, Lisanby SH, Miniussi C, Padberg F, PascualLeone A, Paulus W, Peterchev AV, Quartarone A, Rotenberg A, Rothwell J, Rossini PM, Santarnecchi E, Shafi MM, Siebner HR, Ugawa Y, Wassermann EM, Zangen A, Ziemann U, Hallett M. 2021. Safety and recommendations for TMS use in healthy subjects and patient populations, with updates on training, ethical and regulatory issues: Expert Guidelines. Clin Neurophysiol 132:269-306. doi:10.1016/j.clinph.2020.10.003

Rubinov M, Sporns O. 2010. Complex network measures of brain connectivity: uses and interpretations. Neurolmage 52:1059-1069. doi:10.1016/j.neuroimage.2009.10.003

Ruff CC, Blankenburg F, Bjoertomt O, Bestmann S, Freeman E, Haynes J-D, Rees G, Josephs O, Deichmann R, Driver J. 2006a. Concurrent TMS-fMRI and Psychophysics Reveal Frontal Influences on Human Retinotopic Visual Cortex. Curr Biol 16:1479-1488. doi:10.1016/j.cub.2006.06.057

Ruff CC, Blankenburg F, Bjoertomt O, Bestmann S, Freeman E, Haynes J-D, Rees G, Josephs O, Deichmann R, Driver J. 2006b. Concurrent TMS-fMRI and psychophysics reveal frontal influences on human retinotopic visual cortex. Curr Biol CB 16:1479-1488. doi:10.1016/j.cub.2006.06.057

Ruff CC, Blankenburg F, Bjoertomt O, Bestmann S, Weiskopf N, Driver J. 2008. Hemispheric Differences in Frontal and Parietal Influences on Human Occipital Cortex: Direct Confirmation with Concurrent TMS-fMRI. J Cogn Neurosci 21:1146-1161. doi:10.1162/jocn.2009.21097

Ruzzoli M, Abrahamyan A, Clifford CWG, Marzi CA, Miniussi C, Harris JA. 2011. The effect of TMS on visual motion sensitivity: an increase in neural noise or a decrease in signal strength? J Neurophysio/ 106:138-143. doi:10.1152/jn.00746.2010

Ruzzoli M, Marzi CA, Miniussi C. 2010. The Neural Mechanisms of the Effects of Transcranial Magnetic Stimulation on Perception. J Neurophysiol 103:2982-2989. doi:10.1152/jn.01096.2009 
Sack AT, Kohler A, Bestmann S, Linden DEJ, Dechent P, Goebel R, Baudewig J. 2007. Imaging the brain activity changes underlying impaired visuospatial judgments: simultaneous FMRI, TMS, and behavioral studies. Cereb Cortex N Y N 1991 17:2841-2852. doi:10.1093/cercor/bhm013

Sandrini M, Umiltà C, Rusconi E. 2011. The use of transcranial magnetic stimulation in cognitive neuroscience: A new synthesis of methodological issues. Neurosci Biobehav Rev 35:516-536. doi:10.1016/j.neubiorev.2010.06.005

Schwarzkopf DS, Silvanto J, Rees G. 2011. Stochastic Resonance Effects Reveal the Neural Mechanisms of Transcranial Magnetic Stimulation. J Neurosci 31:3143-3147. doi:10.1523/JNEUROSCI.4863-10.2011

Silvanto J, Cattaneo Z. 2017. Common framework for "virtual lesion" and state-dependent TMS: The facilitatory/suppressive range model of online TMS effects on behavior. Brain Cogn 119:32-38. doi:10.1016/j.bandc.2017.09.007

Silvanto J, Muggleton NG. 2008. New light through old windows: moving beyond the "virtual lesion" approach to transcranial magnetic stimulation. Neurolmage 39:549-552. doi:10.1016/j.neuroimage.2007.09.008

Silvanto J, Muggleton NG, Cowey A, Walsh V. 2007. Neural adaptation reveals state-dependent effects of transcranial magnetic stimulation. Eur J Neurosci 25:1874-1881. doi:https://doi.org/10.1111/j.1460-9568.2007.05440.x

Silvanto J, Pascual-Leone A. 2008. State-Dependency of Transcranial Magnetic Stimulation. Brain Topogr 21:1-10. doi:10.1007/s10548-008-0067-0

Solomon-Harris LM, Rafique SA, Steeves JKE. 2016. Consecutive TMS-fMRI reveals remote effects of neural noise to the "occipital face area." Brain Res 1650:134-141. doi:10.1016/j.brainres.2016.08.043

Sperber C. 2020. Rethinking causality and data complexity in brain lesion-behaviour inference and its implications for lesion-behaviour modelling. Cortex J Devoted Study Nerv Syst Behav 126:49-62. doi:10.1016/j.cortex.2020.01.004

Tadin D, Silvanto J, Pascual-Leone A, Battelli L. 2011. Improved motion perception and impaired spatial suppression following disruption of cortical area MT/V5. J Neurosci Off J Soc Neurosci 31:1279-1283. doi:10.1523/JNEUROSCl.4121-10.2011

Telesford QK, Simpson SL, Burdette JH, Hayasaka S, Laurienti PJ. 2011. The Brain as a Complex System: Using Network Science as a Tool for Understanding the Brain. Brain Connect 1:295-308. doi:10.1089/brain.2011.0055

Tu W, Ma Z, Zhang N. 2021. Brain network reorganization after targeted attack at a hub region. Neurolmage 237:118219. doi:10.1016/j.neuroimage.2021.118219

van de Ven V, Sack AT. 2013. Transcranial magnetic stimulation of visual cortex in memory: Cortical state, interference and reactivation of visual content in memory. Behav Brain Res 236:67-77. doi:10.1016/j.bbr.2012.08.001

van den Heuvel MP, Sporns O. 2013. Network hubs in the human brain. Trends Cogn Sci 17:683-696. doi:10.1016/j.tics.2013.09.012

Vesia M, Yan X, Henriques DY, Sergio LE, Crawford JD. 2008. Transcranial magnetic stimulation over human dorsal-lateral posterior parietal cortex disrupts integration of hand position signals into the reach plan. J Neurophysiol 100:2005-2014. doi:10.1152/jn.90519.2008

Walsh V, Pascual-Leone A. 2003. Transcranial Magnetic Stimulation: A Neurochronometrics of Mind. doi:10.7551/mitpress/6896.001.0001

Watanabe T, Hanajima R, Shirota Y, Ohminami S, Tsutsumi R, Terao Y, Ugawa Y, Hirose S, Miyashita Y, Konishi S, Kunimatsu A, Ohtomo K. 2013. Bidirectional effects on interhemispheric resting-state functional connectivity induced by excitatory and inhibitory repetitive transcranial magnetic stimulation. Hum Brain Mapp 35:18961905. doi:10.1002/hbm.22300 
bioRxiv preprint doi: https://doi.org/10.1101/2022.03.03.482512; this version posted March 4, 2022. The copyright holder for this preprint (which was not certified by peer review) is the author/funder. All rights reserved. No reuse allowed without permission.

Weiskrantz L, Warrington E, Sanders MD, Marshal J. 1974. Visual capacity in the hemianopic field following a restrcted occipital ablation. Brain 97:709-728.

doi:10.1093/brain/97.1.709

Wibral M, Bledowski C, Kohler A, Singer W, Muckli L. 2009. The Timing of Feedback to Early Visual Cortex in the Perception of Long-Range Apparent Motion. Cereb Cortex N Y NY 19:1567-1582. doi:10.1093/cercor/bhn192

Wu Y, Hengen KB, Turrigiano GG, Gjorgjieva J. 2019. Homeostatic mechanisms regulate distinct aspects of cortical circuit dynamics. bioRxiv 790410. doi:10.1101/790410 


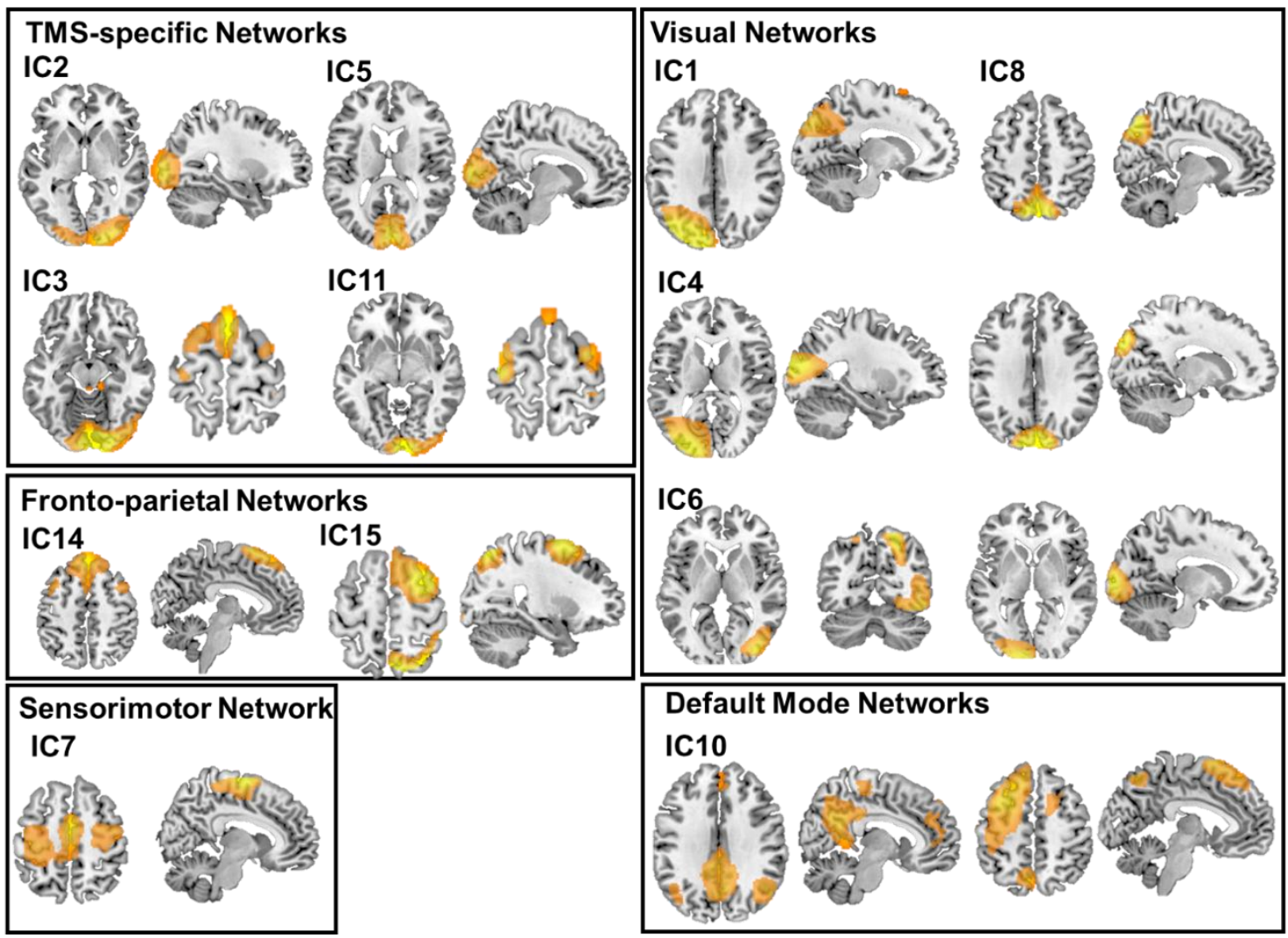

Figure S1: Independent component analysis (ICA) results of TMS (EVA) at rest. Spatial distribution of 15 networks, grouped into functional groups. See Supplementary Table S7 for the Montreal Neurological Institute (MNI) coordinates; 


\section{Supplementary Figure S2 (Task EVA)}
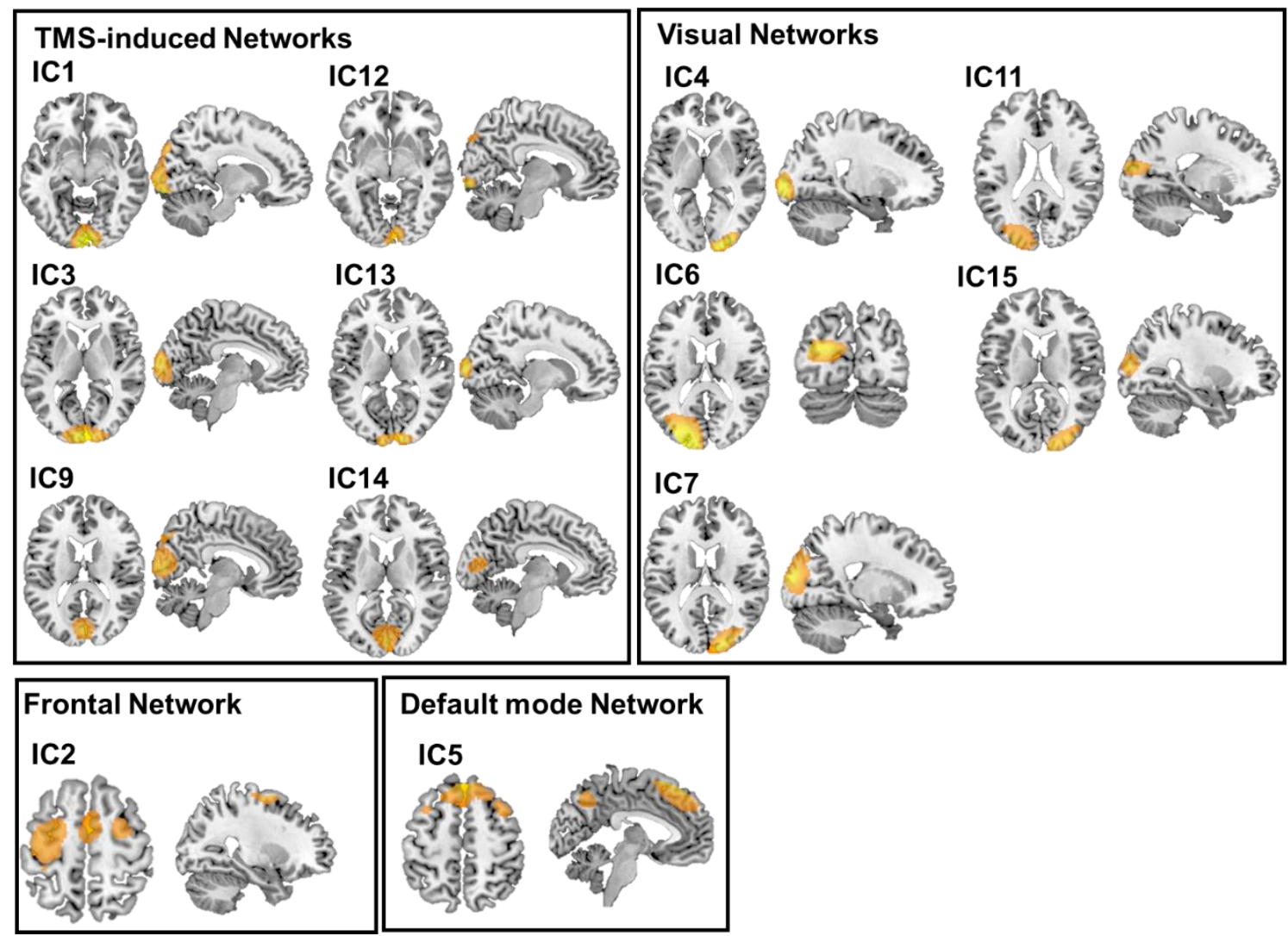

Figure S2: Independent component analysis (ICA) results of the motion discrimination task with $T M S_{(E V A)}$. Spatial distribution of 13 networks, grouped into functional groups. See Supplementary Table 88 for the Montreal Neurological Institute (MNI) coordinates; 

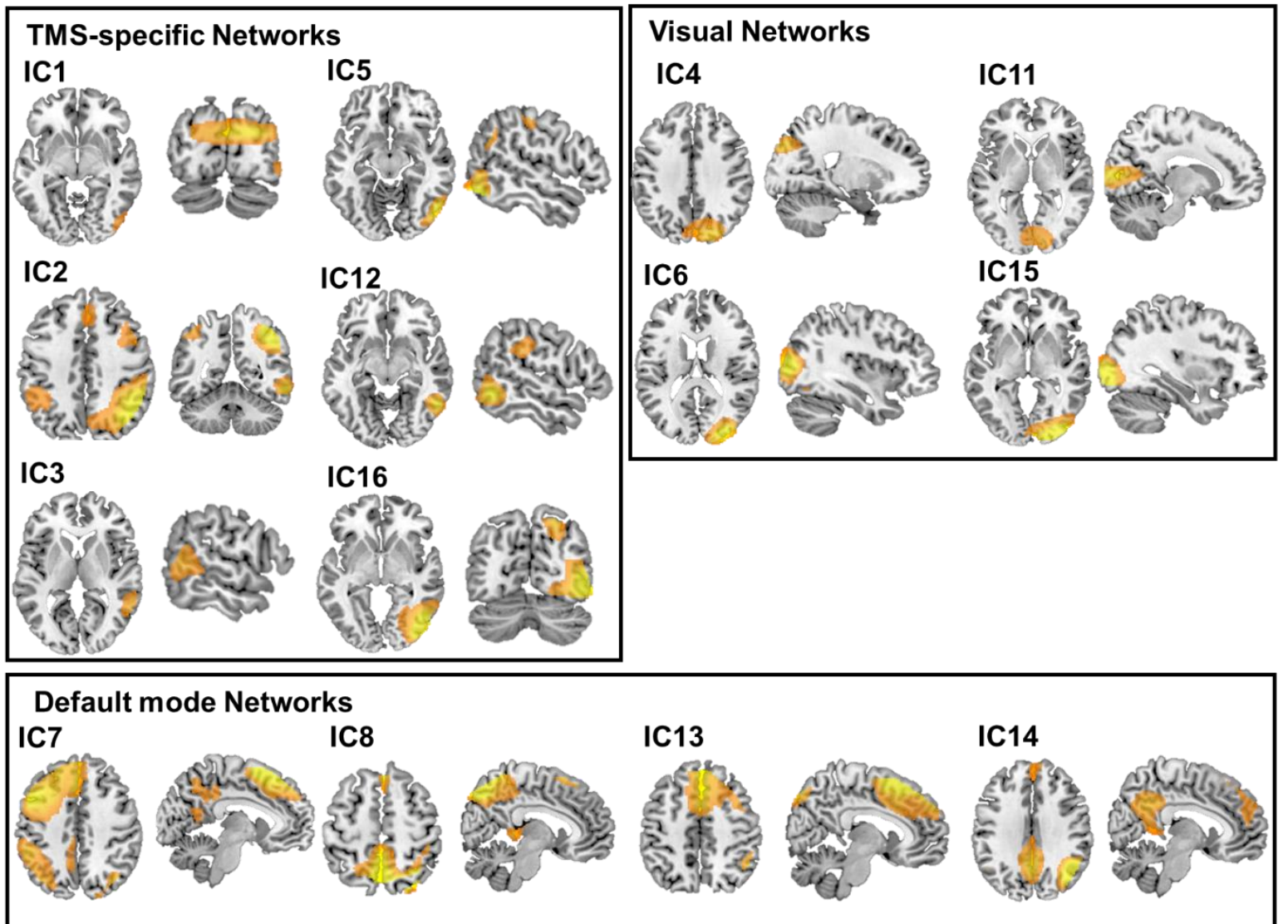

Figure S4: Independent component analysis (ICA) results of TMS (hMT+/N5) $_{\text {at rest. Spatial }}$ distribution of 14 networks, grouped into functional groups. See Supplementary Table S8 for the Montreal Neurological Institute (MNI) coordinates; 
Supplementary Figure S4 (Task hMT+/V5)

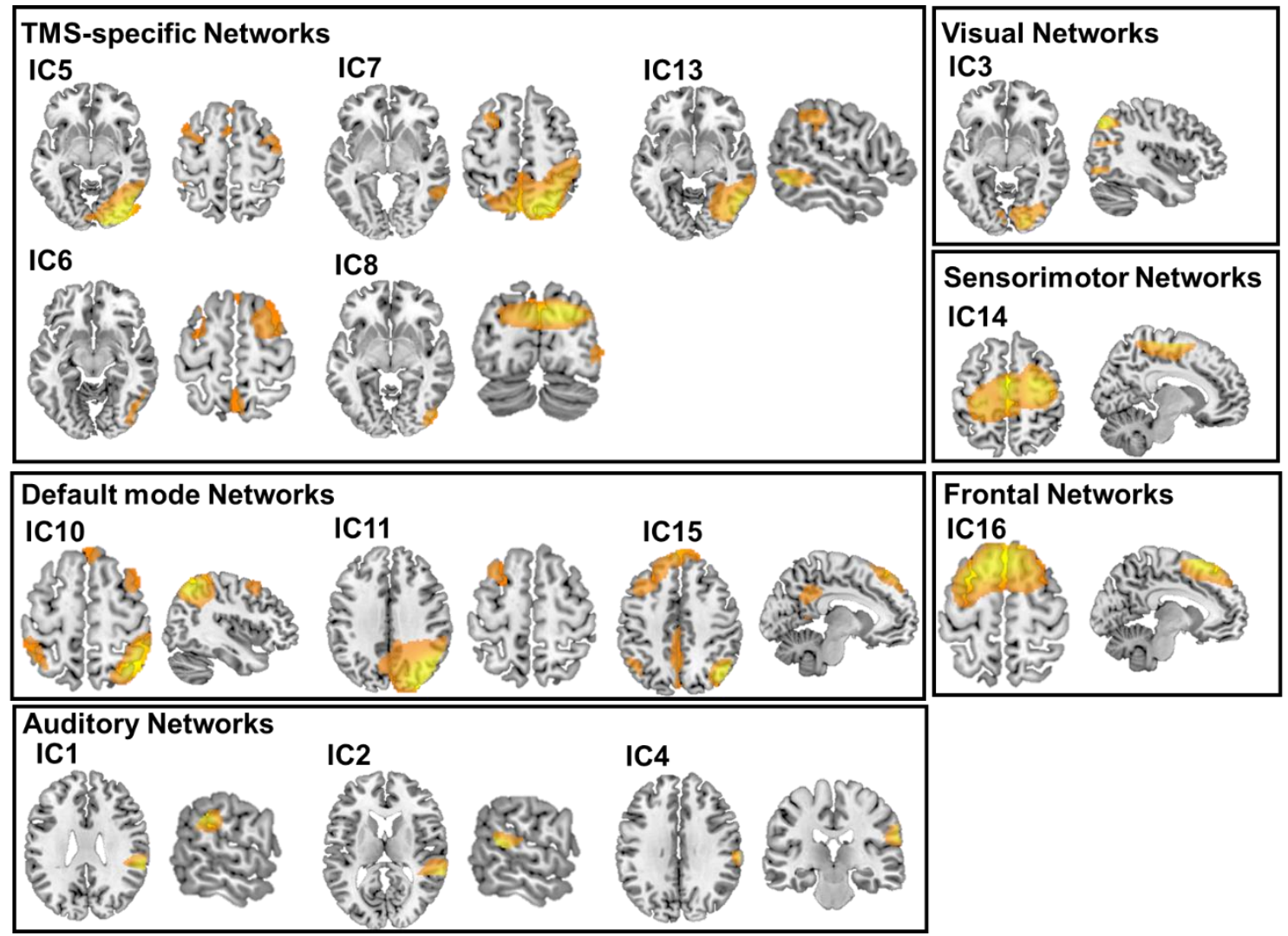

Figure S2: Independent component analysis (ICA) results of the motion discrimination task with

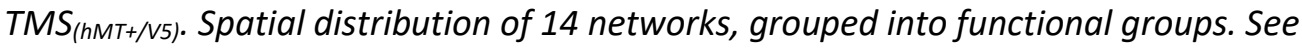
Supplementary Table 59 for the Montreal Neurological Institute (MNI) coordinates; 
Supplementary Table S1 (GLM analysis Rest EVA)

\begin{tabular}{|c|c|c|c|c|c|}
\hline \multirow{2}{*}{ Brain region } & \multirow{2}{*}{ Cluster extent } & \multirow{2}{*}{ Z score } & \multicolumn{3}{|c|}{ Peak MNI coordinate } \\
\hline & & & $x$ & $\mathrm{y}$ & $z$ \\
\hline \multicolumn{6}{|l|}{ noTMS>TMS } \\
\hline EVA (Right & & 4.43 & & & \\
\hline hem.) & 516 & & 6 & -80 & 15 \\
\hline hMT+/V5 (Right & & 3.31 & & & \\
\hline hem.) & 419 & & 51 & -52 & 10 \\
\hline \multicolumn{6}{|l|}{ TMS>noTMS } \\
\hline SMA & 219 & 4.48 & 1 & 2 & 61 \\
\hline FEF & 384 & 3.91 & 23 & 8 & 61 \\
\hline
\end{tabular}

Bilat.: bilateral; hem.: hemisphere; FEF: Frontal Eye Field; EVA: early visual areas; hMT+/V5: motionsensitive medio-temporal visual area; SMA: supplementary motor area. 
bioRxiv preprint doi: https://doi.org/10.1101/2022.03.03.482512; this version posted March 4, 2022. The copyright holder for this preprint (which was not certified by peer review) is the author/funder. All rights reserved. No reuse allowed without permission.

Supplementary Table S2 (GLM analysis Rest hMT+/V5)

\begin{tabular}{|c|c|c|c|c|c|}
\hline \multirow{2}{*}{ Brain region } & \multirow{2}{*}{ Cluster extent } & \multirow[t]{2}{*}{ Z score } & \multicolumn{3}{|c|}{ Peak MNI coordinate } \\
\hline & & & $x$ & $y$ & $z$ \\
\hline \multicolumn{6}{|l|}{ noTMS $>$ TMS } \\
\hline hMT+/V5 (Right & & 4.62 & & & \\
\hline hem.) & 609 & & 39 & -70 & -5 \\
\hline EVA (Right & & 3.47 & & & \\
\hline hem.) & 213 & & 6 & -64 & -7 \\
\hline FEF (Right hem.) & 205 & 4.05 & 12 & 2 & 50 \\
\hline
\end{tabular}


Supplementary Table S3 (GLM analysis Task EVA)

\begin{tabular}{lccccc}
\hline \multirow{2}{*}{ Brain region } & \multirow{2}{*}{ Cluster extent } & \multirow{2}{*}{ Z score } & \multicolumn{4}{c}{ Peak MNI coordinate } \\
& & & $\mathrm{x}$ & $\mathrm{y}$ & $\mathrm{z}$ \\
\hline TMS>noTMS & & 3.34 & -2 & -88 & 20 \\
EVA (bilat.) & 502 & 3.21 & 2 & -11 & 60 \\
SMA (bilat.) & 1843 &
\end{tabular}

Bilat.: bilateral; EVA: primary visual areas; SMA: supplementary motor area; 
bioRxiv preprint doi: https://doi.org/10.1101/2022.03.03.482512; this version posted March 4, 2022. The copyright holder for this preprint (which was not certified by peer review) is the author/funder. All rights reserved. No reuse allowed without permission.

Supplementary Table S4 (GLM analysis Task hMT+/V5)

\begin{tabular}{lccccc}
\hline \multirow{2}{*}{ Brain region } & Cluster extent & Z score & \multicolumn{3}{c}{ Peak MNI coordinate } \\
\hline noTMS>TMS & & & & $y$ & z \\
hMT+/V5 (Right & & 4.73 & & & \\
hem.) & 462 & & 37 & -61 & -5 \\
& 351 & & 8 & -66 & -2
\end{tabular}

Hem.: hemisphere; EVA: early visual areas; hMT+/V5: motion sensitive medio-temporal visual area. 
bioRxiv preprint doi: https://doi.org/10.1101/2022.03.03.482512; this version posted March 4, 2022. The copyright holder for this preprint (which was not certified by peer review) is the author/funder. All rights reserved. No reuse allowed without permission.

Supplementary Table S5 (GLM analysis Task EVA - Visual context)

\begin{tabular}{|c|c|c|c|c|c|}
\hline \multirow{2}{*}{ Brain region } & \multirow{2}{*}{ Cluster extent } & \multirow[t]{2}{*}{ Z score } & \multicolumn{3}{|c|}{ Peak MNI coordinate } \\
\hline & & & $x$ & y & Z \\
\hline \multicolumn{6}{|l|}{$\mathrm{TMS}_{(\mathrm{EVA})-}$} \\
\hline \multicolumn{6}{|l|}{ Mov $>T_{M} S_{(E V A)-S t a t}$} \\
\hline hMT+/V5 (Right & & 4.62 & & & \\
\hline hem.) & 609 & & 47 & -79 & -1 \\
\hline EVA & & & 6 & -78 & 3 \\
\hline
\end{tabular}

Hem.: hemisphere; hMT+/V5: motion sensitive medio-temporal visual area 
bioRxiv preprint doi: https://doi.org/10.1101/2022.03.03.482512; this version posted March 4, 2022. The copyright holder for this preprint (which was not certified by peer review) is the author/funder. All rights reserved. No reuse allowed without permission.

Supplementary Table S6 (GLM analysis Task EVA - visual processing stage)

\begin{tabular}{lccccc}
\hline \multirow{2}{*}{ Brain region } & \multirow{2}{*}{ Cluster extent } & \multirow{2}{*}{ Z score } & x & Peak MNI coordinate & z \\
\hline TMS $_{\text {late }>\text { TMS }}$ early & & & & & \\
FEF (Right hem.) & 426 & 5.03 & 32 & 7 & 69 \\
FEF (Left hem.) & 219 & 3.31 & -24 & 8 & 64 \\
PreCuneus & 679 & 3.32 & -3 & -50 & 57 \\
(bilat.) & \\
Bilat.: Bilateral; Hem.: hemisphere; FEF: Frontal Eye Field; $h M T+/$ V5: motion sensitive
\end{tabular}


Supplementary Table S7 (MNI coordinates of the 15 IC networks for Rest EVA)

\begin{tabular}{|c|c|c|c|c|c|}
\hline \multirow{2}{*}{ Component } & \multirow{2}{*}{ Cluster region } & \multirow{2}{*}{ Cluster extent } & \multicolumn{3}{|c|}{ Peak MNI coordinate } \\
\hline & & & $\mathrm{x}$ & $y$ & $z$ \\
\hline \multicolumn{6}{|l|}{ TMS specific } \\
\hline \multicolumn{6}{|l|}{ Networks } \\
\hline IC2 & EVA (bilat.) & 2343 & 25 & -95 & 24 \\
\hline \multirow[t]{5}{*}{ IC3 } & EVA (bilat.) & 122 & 51 & -48 & 5 \\
\hline & LGN (Right hem.) & 283 & 6 & -98 & -13 \\
\hline & FEF (Right hem.) & 234 & 32 & 35 & 63 \\
\hline & FEF (Left hem.) & 989 & -31 & 37 & 65 \\
\hline & PFC (bilat.) & & -3 & 57 & 20 \\
\hline \multirow[t]{3}{*}{ IC5 } & EVA (bilat.) & 348 & 43 & -73 & 16 \\
\hline & PPC (bilat.) & 3577 & 26 & -59 & 56 \\
\hline & PreFrontal (Left hem.) & 298 & 9 & -21 & 57 \\
\hline \multirow[t]{3}{*}{$\mathrm{IC} 11$} & EVA (Right hem.) & 432 & 1 & -58 & 4 \\
\hline & FEF (Right hem.) & 722 & 30 & 5 & 69 \\
\hline & FEF (Left hem.) & 832 & -30 & 10 & 67 \\
\hline \multicolumn{6}{|c|}{ Visual Network } \\
\hline \multirow[t]{2}{*}{ IC1 } & EVA (Left hem.) & 4420 & -20 & -79 & 25 \\
\hline & $\begin{array}{l}\text { Frontal lobe (Left } \\
\text { hem.) }\end{array}$ & 394 & -20 & 20 & 65 \\
\hline IC4 & EVA (Left hem.) & 3222 & -18 & -69 & 13 \\
\hline IC6 & V5 (Right hem.) & 436 & 46 & -65 & -10 \\
\hline IC8 & PreCuneus (bilat.) & 2655 & 6 & -69 & 44 \\
\hline IC12 & EVA (bilat) & 2034 & -1 & -58 & 32 \\
\hline IC13 & EVA (Left hem.) & 2276 & -16 & -89 & -4 \\
\hline \multicolumn{6}{|l|}{ Sensorimotor } \\
\hline \multicolumn{6}{|l|}{ Network } \\
\hline \multirow[t]{3}{*}{ IC7 } & SM1 (Right hem.) & 1286 & 25 & -20 & 63 \\
\hline & SM1 (Left hem.) & 1643 & -23 & -7 & 60 \\
\hline & SMA (bilat.) & 743 & 3 & 4 & 69 \\
\hline \multicolumn{6}{|l|}{$\begin{array}{l}\text { Fronto Parietal } \\
\text { Networks }\end{array}$} \\
\hline IC14 & Frontal lobe (bilat.) & 3984 & -4 & 29 & 55 \\
\hline \multirow[t]{2}{*}{ IC15 } & PFC (Right hem.) & 3678 & 23 & 9 & 62 \\
\hline & PPC (Right hem.) & 903 & 18 & -65 & 55 \\
\hline \multicolumn{6}{|l|}{$\begin{array}{l}\text { Default Mode } \\
\text { Networks }\end{array}$} \\
\hline \multirow[t]{4}{*}{ IC10 } & PCC(bilat.) & 234 & 38 & 20 & 59 \\
\hline & PPC (Right hem.) & 1384 & 38 & -61 & 31 \\
\hline & PPC (Left hem.) & 984 & -39 & -63 & 34 \\
\hline & Med PFC (bilat.) & 346 & 2 & 34 & 56 \\
\hline \multirow[t]{2}{*}{ IC16 } & PreCuneus (Left hem.) & 1583 & 2 & -64 & 56 \\
\hline & PFC (Left hem.) & 2219 & -13 & 22 & 44 \\
\hline
\end{tabular}

Bilat.: bilateral; hem.: hemisphere; FEF: Frontal Eye Field; EVA: early visual areas; V5: medio-temporal visual area; SMA: supplementary motor area. 
Supplementary Table S8 (MNI coordinates of the 13 IC networks Task EVA)

\begin{tabular}{|c|c|c|c|c|c|}
\hline \multirow{2}{*}{ Component } & \multirow{2}{*}{ Cluster region } & \multirow{2}{*}{ Cluster extent } & \multicolumn{3}{|c|}{ Peak MNI coordinate } \\
\hline & & & $x$ & $y$ & $\mathrm{z}$ \\
\hline \multicolumn{6}{|l|}{ TMS-specific } \\
\hline \multicolumn{6}{|l|}{ Networks } \\
\hline IC1 & EVA (Bilat.) & 1843 & 21 & -93 & -6 \\
\hline IC3 & EVA (Bilat.) & 1557 & -5 & -85 & 2 \\
\hline IC9 & EVA (Bilat.) & 1476 & 3 & -97 & 9 \\
\hline \multirow[t]{2}{*}{ IC12 } & EVA (Bilat.) & 764 & 5 & -88 & -8 \\
\hline & Pre Cuneus (Bilat.) & 579 & 7 & -82 & 23 \\
\hline IC13 & EVA (Bilat.) & 984 & -7 & -92 & 16 \\
\hline IC14 & EVA (Bilat.) & 1243 & -1 & -81 & 8 \\
\hline \multicolumn{6}{|l|}{ Visual Networks } \\
\hline IC4 & EVA (Right hem.) & 763 & 28 & -89 & 5 \\
\hline IC6 & EVA (Left hem.) & 587 & -14 & -93 & 18 \\
\hline IC7 & EVA (Right hem.) & 634 & 30 & -93 & -5 \\
\hline IC11 & EVA (Left hem.) & 423 & -24 & -86 & 18 \\
\hline IC15 & EVA (Right hem.) & 478 & 27 & -89 & 17 \\
\hline \multicolumn{6}{|l|}{ Frontal Network } \\
\hline \multirow[t]{3}{*}{$\mathrm{IC} 2$} & FEF (Right hem.) & 642 & 28 & -2 & 52 \\
\hline & FEF (Left hem.) & 897 & -31 & -1 & 51 \\
\hline & SMA (Bilat.) & 598 & 8 & -5 & 66 \\
\hline \multicolumn{6}{|l|}{ Default Mode } \\
\hline \multicolumn{6}{|l|}{ Networks } \\
\hline \multirow[t]{2}{*}{ IC5 } & Pre Frontal & 2534 & 6 & 43 & 45 \\
\hline & Pre Cuneus & 1243 & 2 & -66 & 43 \\
\hline
\end{tabular}

Bilat.: bilateral; hem.: hemisphere; FEF: Frontal Eye Field; EVA: early visual areas; SMA: supplementary motor area 
Supplementary Table S8 (ICA analysis hMT+/V5 Rest)

\begin{tabular}{|c|c|c|c|c|c|}
\hline \multirow{2}{*}{ Component } & \multirow{2}{*}{ Cluster region } & \multirow{2}{*}{ Cluster extent } & \multicolumn{3}{|c|}{ Peak MNI coordinate } \\
\hline & & & $x$ & $y$ & $z$ \\
\hline \multicolumn{6}{|l|}{$\begin{array}{l}\text { TMS-specific } \\
\text { Networks }\end{array}$} \\
\hline \multirow[t]{3}{*}{ IC1 } & hMT+/V5 (Right & & & & \\
\hline & hem.) & 1343 & 51 & -57 & -7 \\
\hline & PreCuneus (bilat.) & 187 & 33 & -47 & -7 \\
\hline \multirow[t]{6}{*}{ IC2 } & FEF (Right hem.) & 218 & -32 & -24 & 58 \\
\hline & mPFC (bilat.) & 138 & 4 & 15 & 61 \\
\hline & hMT+/V5 (Right & & & & \\
\hline & hem.) & 122 & 51 & -48 & 5 \\
\hline & PPC (Right hem.) & 283 & -3 & -19 & 12 \\
\hline & PPC (Left hem.) & 934 & 27 & 12 & 653 \\
\hline \multirow[t]{2}{*}{ IC3 } & hMT+/V5 (Right & & & & \\
\hline & hem.) & 189 & -31 & 17 & 65 \\
\hline \multirow[t]{4}{*}{ IC5 } & hMT+/V5 (Right & & & & \\
\hline & hem.) & 348 & 43 & -73 & 16 \\
\hline & IPS (Right hem.) & 177 & 26 & -59 & 56 \\
\hline & S1 (Right hem.) & 298 & 9 & -21 & 57 \\
\hline \multirow[t]{3}{*}{ IC12 } & hMT+/V5 (Right & & & & \\
\hline & hem.) & 743 & 51 & -60 & -4 \\
\hline & IPS (Right hem.) & 4420 & -3 & -78 & 2 \\
\hline \multirow[t]{5}{*}{ IC16 } & hMT+/V5 (Right & & & & \\
\hline & hem.) & 721 & 34 & -45 & 61 \\
\hline & PPC (Right hem.) & 523 & 28 & -62 & 58 \\
\hline & FEF (Right hem.) & & 24 & 3 & 57 \\
\hline & FEF (Left hem.) & & -22 & 6 & 55 \\
\hline \multirow{2}{*}{\multicolumn{6}{|c|}{$\begin{array}{l}\text { Visual } \\
\text { Networks }\end{array}$}} \\
\hline & & & & & \\
\hline IC4 & EVA (Right hem.) & 873 & 19 & -78 & 33 \\
\hline IC6 & EVA (Right hem.) & 1034 & 9 & -76 & 20 \\
\hline IC11 & EVA (bilat.) & 756 & 7 & -88 & 12 \\
\hline IC15 & EVA (Right hem.) & 984 & 15 & -85 & 9 \\
\hline \multicolumn{6}{|l|}{$\begin{array}{l}\text { Default } \\
\text { mode }\end{array}$} \\
\hline \multicolumn{6}{|l|}{ Networks } \\
\hline \multirow[t]{4}{*}{ IC7 } & Frontal lobe (Left & & & & \\
\hline & hem.) & 2583 & -5 & 30 & 59 \\
\hline & PPC (Right hem.) & 432 & 33 & -66 & 47 \\
\hline & PPC (Left hem.) & 564 & -45 & -66 & 45 \\
\hline \multirow[t]{3}{*}{ IC8 } & PreCuneus (bilat.) & 219 & 46 & 28 & 44 \\
\hline & LGN (Right hem.) & 132 & 2 & -33 & 14 \\
\hline & Frontal lobe (bilat.) & 319 & 5 & 18 & 64 \\
\hline IC13 & Frontal lobe (bilat.) & 1032 & 10 & 21 & 60 \\
\hline \multirow[t]{3}{*}{ IC14 } & PCC (bilat.) & 1883 & 1 & -49 & 36 \\
\hline & ACC (bilat.) & 1284 & 1 & 54 & 36 \\
\hline & PPC (Right hem.) & 1439 & 14 & -61 & 28 \\
\hline
\end{tabular}


bioRxiv preprint doi: https://doi.org/10.1101/2022.03.03.482512; this version posted March 4, 2022. The copyright holder for this preprint (which was not certified by peer review) is the author/funder. All rights reserved. No reuse allowed without permission.

Bilat.: bilateral; hem.: hemisphere; hMT+/V5: motion-sensitive medio-temporal visual area; FEF: Frontal Eye Field; EVA: early visual areas; MPFC: medial prefrontal cortex; PCC: posterior cingulate cortex; ACC: anterior cingulate cortex; SMA: supplementary motor area; LGN: lateral geniculate nucleus; S1: preimary somatosensory cortex. 
Supplementary Table S9 (MNI coordinates of the 14 IC networks Task hMT+/V5)

\begin{tabular}{|c|c|c|c|c|c|}
\hline \multirow{2}{*}{ Component } & \multirow{2}{*}{ Cluster region } & \multirow{2}{*}{ Cluster extent } & \multicolumn{3}{|c|}{ Peak MNI coordinate } \\
\hline & & & $x$ & $y$ & z \\
\hline \multicolumn{6}{|l|}{ TMS specific } \\
\hline \multicolumn{6}{|l|}{ Networks } \\
\hline \multirow[t]{4}{*}{ IC5 } & hMT+/V5 (Right hem.) & 1343 & 58 & -48 & 1 \\
\hline & FEF (Right hem.) & 187 & 54 & -18 & 45 \\
\hline & FEF (Left hem.) & 218 & -32 & -24 & 58 \\
\hline & PreSMA (bilat.) & 138 & 4 & 15 & 61 \\
\hline \multirow[t]{4}{*}{ IC6 } & hMT+/V5 (Right hem.) & 122 & 51 & -48 & 5 \\
\hline & PreCuneus (bilat.) & 283 & -3 & -19 & 12 \\
\hline & FEF (Right hem.) & 934 & 27 & 12 & 653 \\
\hline & FEF (Left hem.) & 189 & -31 & 17 & 65 \\
\hline \multirow[t]{3}{*}{ IC7 } & hMT+/V5 (Right hem.) & 348 & 43 & -73 & 16 \\
\hline & PPC (bilat.) & 3577 & 26 & -59 & 56 \\
\hline & PreFrontal (Left hem.) & 298 & 9 & -21 & 57 \\
\hline \multirow[t]{2}{*}{ IC8 } & hMT+/V5 (Right hem.) & 132 & 56 & -58 & 4 \\
\hline & PPC (bilat.) & 2232 & 30 & -69 & 60 \\
\hline \multirow[t]{2}{*}{ IC13 } & V5 (Right hem.) & 1687 & 9 & 3 & 45 \\
\hline & PPC (Right hem.) & 587 & 39 & -21 & 20 \\
\hline \multicolumn{6}{|c|}{ Visual Network } \\
\hline \multirow[t]{2}{*}{ IC3 } & EVA (Right hem.) & 4420 & -3 & -78 & 2 \\
\hline & PPC (Right hem.) & 221 & 34 & -45 & 61 \\
\hline \multicolumn{6}{|l|}{$\begin{array}{l}\text { Sensorimotor } \\
\text { Network }\end{array}$} \\
\hline IC14 & SM1 (bilat.) & 4286 & 25 & -20 & 63 \\
\hline \multicolumn{6}{|l|}{ Frontal } \\
\hline IC16 & Frontal lobe (bilat.) & 3984 & -4 & 29 & 55 \\
\hline \multicolumn{6}{|l|}{ Default Mode } \\
\hline \multicolumn{6}{|l|}{ Networks } \\
\hline \multirow[t]{4}{*}{ IC10 } & FEF (Right hem.) & 234 & 38 & 20 & 59 \\
\hline & PPC (Right hem.) & 1384 & 40 & -50 & 59 \\
\hline & PPC (Left hem.) & 984 & 45 & -46 & 54 \\
\hline & mPFC (bilat.) & 346 & 3 & 51 & 42 \\
\hline \multirow[t]{2}{*}{ IC11 } & PPC (Right hem.) & 1583 & 40 & -50 & 59 \\
\hline & PFC (Left hem.) & 219 & 46 & 28 & 44 \\
\hline \multirow[t]{4}{*}{ IC15 } & PPC (Right hem.) & 1032 & 50 & -59 & 44 \\
\hline & PPC (Left hem.) & 783 & -43 & -53 & 44 \\
\hline & PCC & 2984 & 1 & -54 & 42 \\
\hline & PFC & 2439 & 2 & 36 & 46 \\
\hline \multicolumn{6}{|l|}{$\begin{array}{l}\text { Auditory } \\
\text { Networks }\end{array}$} \\
\hline IC1 & STG & 274 & 57 & -52 & 6 \\
\hline IC2 & TPJ & 355 & 54 & -57 & 21 \\
\hline IC4 & STG & 254 & 60 & -43 & 7 \\
\hline
\end{tabular}

Bilat.: bilateral; hem.: hemisphere; FEF: Frontal Eye Field; EVA: early visual areas; $M M T+/ V 5$ :motionsensitive medio-temporal visual area; preSMA: pre-supplementary motor area; PPC: posterior parietal 
bioRxiv preprint doi: https://doi.org/10.1101/2022.03.03.482512; this version posted March 4, 2022. The copyright holder for this preprint (which was not certified by peer review) is the author/funder. All rights reserved. No reuse allowed without permission.

cortex; SM1: preimary sensorimotor cortex; mPFC: medial prefrontal cortex; TPG: temporo-aprietal junction; STG: superior temporal gyrus. 